\title{
Fabrication and Characterization of Layered Graphene Oxide Biocompatible Nano-Film by Various Methods
}

\author{
Himanshu Kharkwal", H.C. Joshi, K.P. Singh \\ Membrane Biophysics and Nanobiosensor Research Laboratory, College of Basic Sciences and Humanities, G.B. Pant University of \\ Agriculture and Technology, Pantnagar Udham Singh Nagar -263145, India \\ *Corresponding Author: h.kharkwal23@gmail.com
}

Copyright $\bigcirc 2018$ by authors, all rights reserved. Authors agree that this article remains permanently open access under the terms of the Creative Commons Attribution License 4.0 International License

\begin{abstract}
The present study includes preparation, fabrication and characterization of GO, GO coated PCTE and Egg membrane respectively. Characterization of GO was done by UV-Visible spectrophotometery, Fourier Transform Infrared spectroscopy (FT-IR), Energy Dispersive Spectroscopy (EDS), and Scanning Electron Microscopy (SEM). Different membranes i.e. PCTE (Polycarbonate track etch membrane) and egg membrane are used for the coating of graphene oxide. The egg membrane was isolated from the egg shell by dipping the egg in $8 \% \mathrm{HCl}$ solution. These membrane i.e. PCTE and egg membrane were then fabricated with graphene oxide by drop casting method and vacuum filtration. The coated membrane was then characterized by different imaging technique such as FE-SEM, Inverted microscopy, FT-IR, and EDX. Based on the characterization best suited method for coating was determined and we found vacuum filtration method as the best method for coating. The simple (non-coated) and GO coated membrane of Egg and PCTE were then used for checking the potential gradient across the membrane by using digital multimeter and from this we came to conclusion that the potential gradient across the GO coated PCTE membrane is highest and lowest potential is of GO coated Egg membrane. Above all we found that GO coated egg membrane is highly beneficial and cost effective as compared to artificial membranes.
\end{abstract}

Keywords Graphene Oxide (GO), Polycarbonate Track Etched (PCTE) Membrane, Fourier Transform Infrared Spectroscopy (FT-IR), Energy Dispersive Spectroscopy (EDS), and Scanning Electron Microscopy (SEM)

\section{Introduction}

Nanoscale materials or nanomaterial are defined as a group of materials in which one of the dimensions must be less than 100 nanometers. Some nanomaterial's occurred naturally, but of precise interest are engineered nanomaterial's (EN). The property that makes engineered nanomaterials stand out among the other materials is their small size of nano order. Their small size at the molecular (nano-meter) level possesses innovative properties which are usually not seen in the materials of conventional size. Nanomaterial's specialty lies with the reason that, at this Nanoscale region, material starts exhibiting unique magnetic, optical and electrical properties. Applications of nanomaterial's existence is intensely felt in various areas like healthcare, smart textiles, prostheses, implants, energy generation and conservation with energy producing materials and extremely effective batteries, defense, terrorism, security, and surveillance [1].

Nano phase engineering has been used in number of structural and functional materials, organic, inorganic, catalytic, optical, electric, magnetic and electronic functions. In recent years, Signal amplification on bio functional nanomaterials has gained importance due to its ultrasensitive bioassays. The nano scaled constituents are biocompatible, due to which it interacts with environment as transporters of biological recognition elements. For attaining better performance for bio-sensing for the functionalization of nanomaterials with biomolecules there are two methods namely, non-covalent interaction and covalent route. Bio-functional nanomaterials have not only ability for signal triggering and exact recognition but also electronic and optical signal tags for strengthening the detected signals [2].

Biocompatibility is defined as "presence of the mildness of the relation between a physical and its biological environment" on the basis of drug delivery [3]. Accuracy of biocompatibility is accomplished, when a material interacts with given body without carrying unacceptable toxic, immunogenic, carcinogenic and thrombogenic responses.Biocompatible nanomaterials have revolutionized many features in protective and therapeutic healthcare, medical devices, tissue repair, bioassay technologies, drug delivery systems, diagnostic techniques and replacement technologies. [4]. 
Biocompatible nanomaterials can be replacement for natural materials which can function with the living systems. Research in the field of bio-nanomaterial has opened new doors in two important fields of life science and material science,[5] which has examined the biocompatibility of graphene-oxide. Biosensors like graphene-oxide based glucose biosensor have been developed recently. The biocompatibility of synthesized graphene-oxide nano sheets with human cells, specifically in retinal pigment epithelium (RPE) cells was examined. Micro porous graphene oxide shows good biocompatibility and has potential benefits in cell attachment and proliferation. Carbon resources have acquired a great interest in past decades in the field of nano science area. The use of carbon nanomaterials has raised the possibilities of charge transfer on bio electrochemical devices, which includes the modification of electrodes with various forms of carbon at specific nanometre range like carbon powder, graphene sheets, carbon nanotubes and carbon capsules respectively. The fundamental electronic properties of carbon materials can be clarified based on the nature of carbon attachment in their different form allotropes.Among all carbon-nanomaterial two compounds namely, graphene and graphene oxide (oxide of graphene) has acquired tremendous interest between physicist, chemists and materials scientists. Graphene exists in two-dimensional (2-D) sheet of carbon atoms and with configuration which is hexagonal. It is in $\mathrm{sp}^{2}$ hybridized state with $\mathrm{sp}^{2}$ bonds. Due to these specific types of bonds and electron arrangement, graphene has amazing properties. It has a large surface area, Hall effect, a band gap which is tunable, high room-temperature, huge mechanical power, high thermal conductivity and elasticity respectively [6].

Graphite has carbon-carbon bond with $\mathrm{sp}^{2}$ hybridization and weak bond energy amongst the head-to-head layers and bond with in and out of plane of p-orbitals respectively [7]. Graphene is a well-known material which shows exceptional properties such as thermal, electrical and mechanical which are due to its unique structure which are an atom thick. It is an allotrope of carbon with $\mathrm{sp}^{2}$ hybridized bonds and bond length of 0.142 nanometres. Graphene and its derivatives such as graphene oxide, reduced graphene oxide have turn out to be best emerging nano building blocks for membrane parting in various tuneable physicochemical properties and laminar processes. Graphene has molecular separation properties, so graphene membranes are used in the refining water and gases.Graphene oxide is nothing but graphene which is improved by chemical means and contains several oxygen functional compounds i.e. oxygen, carbon and hydrogen. Graphene oxide can be effortlessly dispersed in organic solvents, water, and various matrixes, due to the presence of oxygen functional groups. It shows vital property when mixed with the ceramic or polymer-matrixes for increasing two different properties namely, electrical and mechanical property. The material containing graphene-oxide has high strength and toughness due to the presence of divalent ions. Chemical investigation of graphene-oxide has revealed that the oxygen to carbon ratio is about one part of oxygen to three parts of carbon. In properties like electrical conductivity, graphene-oxide is often categorized under an electrical insulator, due to the interference of its $\mathrm{sp}^{2}$ bonding networks. Improvement in the hexagonal lattice changes the electrical conductivity and reduction of the graphene oxide. Graphene Oxide can be reduced chemically to reduced graphene-oxide by means of the modified hummer's method. Reduced graphene-oxide (RGO) is favoured over graphene as it is more electrically conducting than graphene due to the presence of oxygen functional groups.

Conductivity of a substance is defined as "the ability or influence to bear or transmit heat, electricity or sound". Their SI unit of conductivity is Siemens per meter $[\mathrm{S} / \mathrm{m}]$ and the U.S. customary units milli-mhos per centimeter $[\mathrm{mmho} / \mathrm{cm}]$. Its symbols are $\mathrm{k}$ or $\mathrm{s}$.

Electrical conductivity may be defined as "the ratio among the current density $(\mathrm{J})$ and electric field intensity (e)". The reciprocal of electrical conductivity is resistivity,

$$
\mathrm{s}=\mathrm{J} / \mathrm{e}=1 / \mathrm{r} \text {. }
$$

Conductivity measurements are discarded normally due to different environmental and industrial applications as a quick, reliable and economical way of computing the ionic content in solution [8]. The amount of product conductivity is the best way to monitor and drift the performance of water purification systems.

Single-layered transferable graphene nano-sheets were first obtained by two different methods namely mechanical exfoliation ("Scotch-tape" method) [9]. In addition, as of the huge amount of oxygen-bearing functional groups, GO shows outstanding hydrophilicity, and is fairly easily dispersed in water and even in former solvents through additional modification making it easier to transport, handle, functionalize, and deposit than innate graphene [10]. The determination of exact construction of GO is very difficult. The lattice interruption is reproduced by an enhancement in interlayer arrangement from $0.335 \mathrm{~nm}$ for graphite to values greater than $0.625 \mathrm{~nm}$ for GO. Brodie in 1859 was the first one who synthesis the GO, the procedure followed by him included the addition of great amount of potassium chlorate to a slurry of graphite in presence of fuming nitric acid. Staudenmaier in 1898 followed the same procedure but with some changes, he gradually added the chlorate to the reaction mixture of sulfuric acid and fuming nitric acid. This small alteration in the procedure gave a simple rule for production of GO having high oxidation state [11].

One of the first projected applications of graphene is linked to the conductivity of graphene being extremely high [12]. Various transistors have been developed such as Ultra-thin graphene transistors [13].Researchers examining 
the storage properties of graphene oxides have revealed that indium tin oxide electrodes altered with graphene oxide and polymers exhibit the write-read-erase-read-rewrite series for a non-volatile memory device [14].Subsequent graphene oxide-based devices have arose which exhibit data capacities of 0.2 Tbits $\mathrm{cm}^{3}$, which put into perspectives is the equivalent of around ten times the storage of current freely available 16 GB USB flash drives [15].Such graphene based super capacitors are an sensational prospect as they could donate to green energy solutions by use in electronic trains, cars and perhaps even one day, airplanes [16].[17]prepared Graphene-based clear conducting films. The resulting graphene films influenced an excellent electrical conductivity with a great transparency.

Accumulation of graphene oxide (GO) nano sheets into laminar assemblies via coating or filtration approaches, as long as rapid and selective nano-channels of two dimensions for transportation of molecules of small size. The groundbreaking work done by Geim et al. (2004) establish the theory that sub micrometer-thick laminates made from graphene oxide can be entirely impermeable to gases, vapors and liquids, and still it allow unhindered permeation of water. Since then, gathered graphene oxide membranes have many applications like refinement of water and solvent dehydration.

Furthermore, graphene-based laminates also tends to display the very useful gas separation characteristics if we can carefully control their heaping structures. Apart from the entirely-graphene membranes, graphene-based compounds, which usually combine graphene or graphene oxide nano sheets through polymers or inorganics, have expanded ground as a means of refining the selective permeation and anti-fouling characteristic of the pristine membranes. Different approach to create graphene-based membranes influence different microstructures and pathways for transportation, empowering them, which thereafter can be applied for numerous membrane processes, for example pressure filtration (e.g., ultrafiltration, reverse osmosis, Nano filtration, and forward osmosis), gas separation and evaporation.

\section{Material \&Methods}

The work encompasses on the preparation of graphene oxide via modified Hummers method and then characterizing it with the help of UV-VIS spectroscopy, FTIR, etc. which is then followed by the fabrication of thin nano layer of graphene oxide on PCTE and egg membrane by various methods for example vacuum filtration and drop cast methods, the coated GO nano film on PCTE and Egg membrane is then further characterized with the help of inverted microscopy, FT-IR, FE-SEM, EDX, etc. and then choosing the best fabricating method for coating the GO nano films on PCTE and egg membrane based on the characterization, which would set the base line for carrying out future experiments. All the chemicals and solvents used in the study were of analytical grade. Graphite power (Sigma), Hydrochloric acid (Himedia), Sulphuric acid (Himedia), Phosphorouspentaoxide (Sigma), Potassium permagnate (Himedia) are used.

\subsection{Experimental Methodology}

\subsubsection{Preparation of Graphene Oxide}

Graphene oxide is prepared from graphite powder by modified Hummer's method. The graphene oxide was produced by graphite oxide exfoliating in distilled water with ultrasonic waves.

\section{Procedure}

Graphite powder $(2 \mathrm{gm}), \mathrm{K}_{2} \mathrm{~S}_{2} \mathrm{O}_{8}(1 \mathrm{~g})$, and $\mathrm{P}_{2} \mathrm{O}_{5}(1 \mathrm{~g})$ were added into solution of highly concentrated $\mathrm{H}_{2} \mathrm{SO}_{4}(3$ $\mathrm{mL}$ ). The mixture was retained at $80^{\circ} \mathrm{C}$ for $6 \mathrm{~h}$. Then cooled/chilled down to room temperature then diluted with $200 \mathrm{ml}$ of DDW. The diluted fusion was filtered and washed to confiscate the residual acid till the $\mathrm{pH}$ value of rinse water turn out to neutral. The product was dehydrated under ambient condition for 3 consecutive days. This preoxidized graphite powder was here after subjected to oxidation by means of Modified Hummers' method. The preoxidized graphite powder $(1 \mathrm{~g})$ was placed into concentrated $\mathrm{H}_{2} \mathrm{SO}_{4}(23 \mathrm{~mL})$ at $8^{\circ} \mathrm{C}, \mathrm{KMnO}_{4}(3 \mathrm{~g})$ was added slowly with stirring and ice-bath chilling, then the mixture was agitated at $35^{\circ} \mathrm{C}$ for $2 \mathrm{~h}$ and water $(47 \mathrm{~mL})$ was added. In $15 \mathrm{~min}$, the mixture reaction was terminated by adding a huge amount of water $(14 \mathrm{~mL})$ and $30 \% \mathrm{H}_{2} \mathrm{O}_{2}$ solution $(2.5 \mathrm{~mL})$. The mixture was washed and filtered by $1: 10 \mathrm{HCl}$ solution in order to take away metal ions. Mixture was wash away with distilled water till the eluent reached neutral $\mathrm{pH}$. The GO product was diluted in water forming $1 \mathrm{mg} / \mathrm{ml} \mathrm{GO}$ dispersion. To obtain smaller sized GO flakes, this dispersion was allowed to undergo 3 cycles each of 15 seconds of ultra-sonication with amplitude of 30 . Centrifugation of 15 min with $10000 \mathrm{rpm}$ was carried out for further separation of smaller and large sized GO flakes. Then supernatant with smaller sized flakes was collected and preserved for use in further experiment.

\subsubsection{Biophysical Characterization of Graphene Oxide}

The characterization of Graphene Oxide (GO) was done with Double Beam UV- Visible Spectrophotometer and Fourier Transform Infrared spectroscopy (FT-IR).

\subsubsection{UV/Visible Spectrophotometer Study}

Absorption spectra were taken in a range of 200-300 $\lambda$ on a UV-5704M, UV-visible Double beam spectrometer (Electronics Corporation of India Ltd.). The aqueous mixture or suspensions of graphene oxide were utilized as the UV-VIS samples, and the clean/pure water was used as reference scanning of samples was performed from $200 \mathrm{~nm}$ to $300 \mathrm{~nm}$. 


\subsubsection{FT-IR Study}

A FT-IR spectrum of $1 \mathrm{mg} / \mathrm{ml}$ GO suspension was recorded in the range of 1000-4000 $\mathrm{cm}^{-1}$. Before proceeding to the main step nitrogen purging was performed till the background peak of $\mathrm{CO}_{2}$ was completely disappeared .This eliminates background noise in the final spectra due to the presence of $\mathrm{CO}_{2}$. IR Spectra of methanol was recorded and treated as a background for the sample as GO suspension was prepared in methanol. After that $1 \mathrm{ml}$ of GO suspension was poured on to the chamber plate and allowed to transmit IR radiations through it. After 32 repeated cycles FT-IR spectra of $1 \mathrm{mg} / \mathrm{ml} \mathrm{GO}$ suspension was recorded and analyzed.

\subsubsection{Scanning Electron Microscopy (SEM) Study}

In scanning electron microscopy the prepared samples of the GO flakes were coated with a thin layer of gold using ion sputter technique. Gold coating is done to prevent morphological and surface changes. SEM was operated at a voltage of about $5 \mathrm{Kv}$ and after impinging of focus of beam of electron on the sample surface, in this we were more concerned about signals emitted as the secondary electron. Highly magnified images of the surface of sample were detected, recorded and saved in PC. Although during the process of the interaction of electron beam with surface of specimen various signal are emitted such as secondary electron, backscattered electron, auger electrons characteristic X-ray etc. but we primarily make use of secondary electron. Secondary electron emitted from the outermost shell of the sample atoms depicts the surface morphology of the sample of the membrane up to a resolution of $5 \mu \mathrm{m}$.Scanning electron microscopy (SEM) images (including high resolution images) were acquired using a JEOL JSM-6610/LV/A/LA scanning electron microscope (JEOL Ltd., Japan) operated at $200 \mathrm{kV}$.

\subsubsection{Egg Membrane Extraction}

Hen egg membrane was extracted by dissolving egg in $8 \%$ $200 \mathrm{ml} \mathrm{HCL}$ solution.Basic step in the extraction of hen egg membrane are as follow:-

(a)Raw egg of hen was taken and small hole with the help of niddle is made at its top edge (b). After that albumin and yolk is withdrawn from it (c). Now what I got is hard shell of egg without albumin and yolk. $200 \mathrm{ml}$ of $8 \% \mathrm{HCL}$ is made and poured in a $500 \mathrm{ml}$ beaker which is followed by immersing egg in it (d). Caution wear hand gloves for immersing egg in HCL solution, Immersed egg membrane liberate bubbles (e) until we get membrane (f) in our hand by completely dissolving outer egg shell in the HCL solution. It would approximately take 10 to 15 minute to completely dissolve outer egg shell so as to get pure membrane.

Nano film layer of graphene oxide was coated on egg and polycarbonate track etch membrane (PCTE) by drop cast and vacuum filtration method.

\subsubsection{Surface Modification of PCTE by Vacuum Filtration Method}

Four polycarbonate membranes each of $50 \mathrm{~nm}$ pore size was modified by coating it with $1 \mathrm{ml}$ of Graphene oxide synthesized in previous step on each membrane. Then it is kept for drying at room temperature.

\subsubsection{Surface Modification of Egg Membrane by Vacuum Filtration Method}

Four egg membranes were modified by coating it with 1 $\mathrm{ml}$ of Graphene oxide synthesized in previous step on each membrane. Then it is kept for drying at room temperature.

\subsubsection{Surface Modification of Polycarbonate Track Etch Membrane (PCTE) by Drop Cast Method}

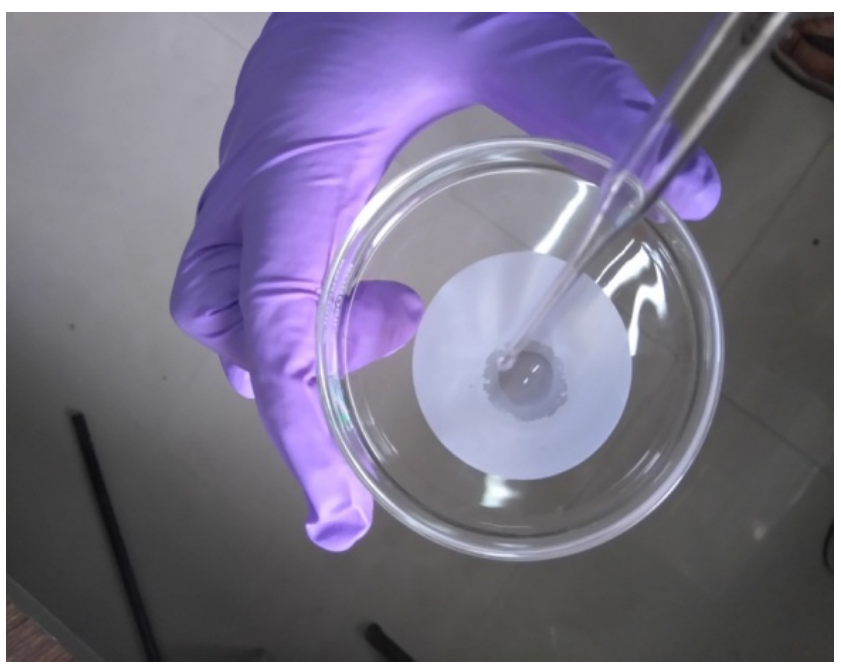

Figure 1. Drop Casting on PCTE membrane

Four polycarbonate membranes each of $50 \mathrm{~nm}$ pore size was modified by coating it with 1 drop of Graphene oxide synthesized in previous step on each membrane by drop casting.Drop casting is done by the help of dropper .One drop $1 \mathrm{mg} / \mathrm{ml}$ GO suspension was casted on PCTE membrane. Then it is kept for drying at room temperature.

\subsubsection{Surface Modification of Egg Membrane by Drop Cast Method}

Four eggs membrane were modified by coating it with 1 drop of Graphene oxide synthesized in previous step on each membrane by drop casting. Drop casting is done by the help of dropper.One drop $1 \mathrm{mg} / \mathrm{ml} \mathrm{GO}$ suspension was casted on egg membrane. Then it is kept for drying at room temperature.

\subsubsection{Characterization of Coated Membrane}

The GO coated PCTE and Egg membrane was characterized by inverted microscopy, FT-IR, energy-dispersive spectroscopy (EDS),FE-SEM, techniques and interaction of $\mathrm{GO}$ with membrane was analyzed. 


\subsubsection{Inverted Microscopy}

The inverted microscope is used for the primary observation of the GO coating on the PCTE membrane. An inverted microscope is the microscope with its light source and condenser at the top, above the stage pointing down, while the objective and turret are below the stage pointing up. This is also used in micromanipulation applications where space above the specimen is required for manipulator mechanism and the micro tool they hold, and in metallurgical application where polished sample can be placed on top of the stage and viewed from underneath using reflecting objectives. The stage on an inverted microscope is usually fixed, and focus is adjusted by moving the objective lens along a vertical axis to bring it closer to or further from the specimen. The focus mechanism typically has a dual concentric knob for coarse and fine adjustment. Depending on the size of the microscope, four to six objective lenses of different magnifications may be fitted to a rotating turret known as a nose peace. These microscopes may also be fitted with accessory for fitting still and video cameras, fluorescence illumination, confocal scanning and many other applications. The normal and GO coated membrane was placed on petri dish (borosil) one by one and the micrograph was recorded at $40 \mathrm{X}$.

\subsubsection{FT-IR Study}

FT-IR spectra of $1 \mathrm{mg} / \mathrm{ml} \mathrm{GO}$ suspension coated PCTE membrane was recorded in the range of $500-4000 \mathrm{~cm}^{-1}$. IR Spectra of non-GO coated PCTE membrane was recorded and treated as a background for the sample. After that GO coated membrane was fitted in the chamber plate and allowed to transmit IR radiations through it. After 32 repeated cycles FT-IR spectra of GO- coated PCTE membrane was recorded and analyzed.

\subsubsection{X- Rays Electron Dispersion Study (EDS)}

The EDX/EDS study was used for elemental characterization of the GO coated membrane. Elemental analysis of chemical characterization of graphene oxide coated membrane was performed by BURKER 127EV XRay's Electron-dispersive spectroscopy. The system consist of three main components: an X- ray chamber separated from the SEM chamber by a very thin polymer window pulse processing circuitry which determines the energy of the detected X-rays; and analyser equipment, which interprets the X-ray data and display it on a computer screen. Characteristic $\mathrm{x}$-rays can be generated in a sample when electrons of a minimum kinetic energy are incident on it. The incident electrons excite the atoms in the sample and as the atom relax electrons moves from outer electron shells to inner ones. During this transition the electron give off energy in the form of photons. The x-ray detector is housed inside a metal tube, which is inserted into the SEM chamber so that the detector is very close to the final aperture of the SEM column and pointed at the surface of the specimen. Thus some of the emitted x-rays will pass through the thin polymer window onto the surface of the detector. The detector is semiconductor made of silicon doped with lithium. X-rays striking the semiconductor create an electrical charge within the semiconductor. This charge is then analysed to determine the $\mathrm{x}$-ray energy and the number of $\mathrm{x}$-rays being emitted. A cryostat consisting of liquid nitrogen-filled Dewar, is mounted on the side of detector housing, through thermal contact, the liquid nitrogen (LN2) keeps the detector cold around $90 \mathrm{~K}$. The electronic noise from circuit at room temperature is so high that no usable signal can be detected. The low temperature of $\mathrm{LN} 2$ reduces the thermal noise to acceptable levels. Additionally, a voltage is applied to the detector during operation, and at room temperature, the $\mathrm{Li}$ in the detector is mobile enough that it can diffuse through the silicon in response to the potential difference, destroying the detector. The LN2 prevents this from happening.

\subsubsection{Measurement of Potential Across Different Membranes}

Potential is basically define as the ability of work done per unit charge in carrying infinitesimal point charge through a common reference point to a given point. Its symbol is denoted by "V".

\subsubsection{Coating of Silver to Make Silver Chloride Electrode for Measuring Potential}

Small pure four silver electrodes were made. Then we have coated it with chloride to convert silver electrode base to silver chloride electrode by the use of Keithley digital multimeter instrument model number DMM7510 installed at Uttrakhand Council of Biotechnology Haldi. Coating was done as follow:-Freshly $0.1 \mathrm{M} 200 \mathrm{ml} \mathrm{HCl}$ was made then from it $50 \mathrm{ml}$ was taken at small $50 \mathrm{ml}$ beaker which was followed by dipping two silver electrode base in it then positive electrode (red in colour) is attached with the silver electrode to coat and negative electrode (black in colour) is attached with the another silver electrode which would we taken as reference electrode, no coating will take place in this reference electrode then it was preceded by setting the voltage to 1.5 volt and current to $10 \mathrm{~mA}$, after setting the current and voltage instrument was turned for coating after 45 minute coating was done. The coated region of electrode was turned black. Henceforth our silver chloride electrode was ready for measuring the potential across membrane.

\subsubsection{Preparation of Different Molar Concentration of Sodium Chloride and Magnesium Chloride}

$200 \mathrm{ml}$ of $1 \mathrm{M}$ and 0.1 Mconcentration of sodium chloride (monovalent ion) and magnesium chloride (divalent ion) was made.

\subsubsection{Attachment of Membranes to Micro Tubes}


Different membrane that is simple PCTE,GO coated PCTE,EGG and GO coated Egg membrane were attached to micro tubes mouth and lower part of micro tube was cut so as to put solution as well as electrode in it since mouth of micro tube is shut off or covered by membranes.

\subsubsection{Measurement of Potential}

Measurement of potential across different membrane was taken after whole set up was ready. $1 \mathrm{M} \mathrm{NaCl}$ was filled on micro tube with attached PCTE membrane and 0.1M $\mathrm{NaCl}$ was filled full on test-tube, in it micro tube with attached membrane was placed in such a way that its membrane touches the solution of test-tube one electrode was then fixed at micro tube and another electrode was fixed at test tube and then consecutive potential measurement was taken at a time interval of ten second for 1 minute. This same procedure is then followed for magnesium chloride.

\subsubsection{Measurement of Potential across GO Coated PCTE Membrane}

$1 \mathrm{M} \mathrm{NaCl}$ was filled on micro tube with attached PCTE membrane and $0.1 \mathrm{M} \mathrm{NaCl}$ was filled full on test-tube, in it micro tube with attached membrane was placed in such a way that its membrane touches the solution of test-tube one electrode was then fixed at micro tube and another electrode was fixed at test tube and then consecutive potential measurement was taken at a time interval of ten second for 1 minute. This same procedure is then followed for magnesium chloride.

\subsubsection{Measurement of Potential across Egg Membrane}

$1 \mathrm{M} \mathrm{NaCl}$ was filled on micro tube with attached Egg membrane and $0.1 \mathrm{M} \mathrm{NaCl}$ was filled full on test-tube, in it micro tube with attached membrane was placed in such a way that its membrane touches the solution of test-tube one electrode was then fixed at micro tube and another electrode was fixed at test tube and then consecutive potential measurement was taken at a time interval of ten second for 1 minute. This same procedure is then followed for magnesium chloride.

\subsubsection{Measurement of Potential across GO Coated EGG Membrane}

$1 \mathrm{M} \mathrm{NaCl}$ was filled on micro tube with attached Egg membrane and $0.1 \mathrm{M} \mathrm{NaCl}$ was filled full on test-tube, in it micro tube with attached membrane was placed in such a way that its membrane touches the solution of test-tube one electrode was then fixed at micro tube and another electrode was fixed at test tube and then consecutive potential measurement was taken at a time interval of ten second for 1 minute. This same procedure is then followed for magnesium chloride.

\section{Result and Discussion}

\subsection{Synthesis of Graphene Oxide}

Graphene oxide was synthesized by modified Hummer's method in which graphite was treated with highly oxidizing agents under ideal condition for graphene oxide synthesis. The coal black thin ordered graphene oxide flakes thus obtained are shown in fig. 2 .

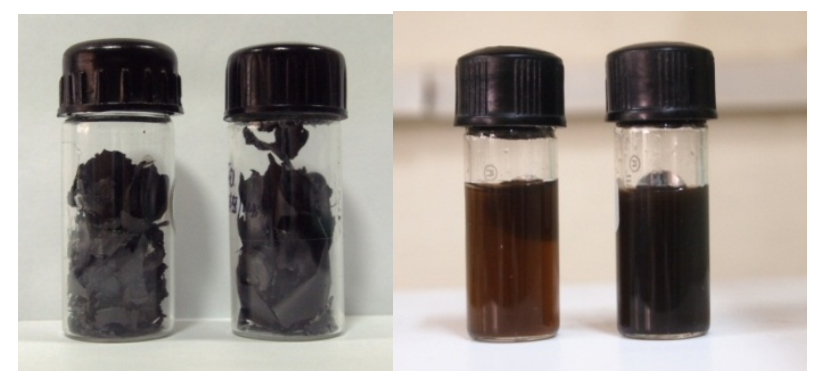

Figure 2.(a) Graphene oxide flakes (b)Graphene oxide dispersion

The graphene oxide flakes was then used to make the $100 \mathrm{ml}$ suspension(few layered GO ) of concentration $1 \mathrm{mg} / \mathrm{ml}$ that is $1 \mathrm{mg}$ of obtained graphene oxide flakes was suspended to $1 \mathrm{ml}$ of ultrapure water then suspension was subjected to ultra-sonication for around 6 hour with temperature between $15^{\circ} \mathrm{C}$ to $30^{\circ} \mathrm{C}$. The synthesized yellow-brown aqueous suspension of $\mathrm{GO}$ was stored at room temperature (as shown in fig. 2 ) and was used for further PCTE and egg membrane modification/coating.

\subsection{Characterization of Graphene Oxide}

The GO flakes and few layered GO was Characterized using microscopic and spectroscopic techniques; UV-Vis spectroscopy, FT-IR, SEM and EDX was done to characterize the GO film.

\subsubsection{UV-Vis Spectroscopy}

UV-Vis spectroscopy is an optical technique which measures the energy absorbed by the solution electrons when irradiated by UV rays and visible regions rays .The ultraviolet spectrum is simply plot of wavelength of light absorbed versus the absorption intensity (absorbance or transmittance).The UV-Vis was done at wavelength $200 \mathrm{~nm}$ to $300 \mathrm{~nm}$ and we got our highest absorption peak at $231 \mathrm{~nm}$ (in Fig.3), which gave us conformation that the GO synthesized by us is correct because a properly synthesized GO shows its highest absorption peak at the same peak which we got. 


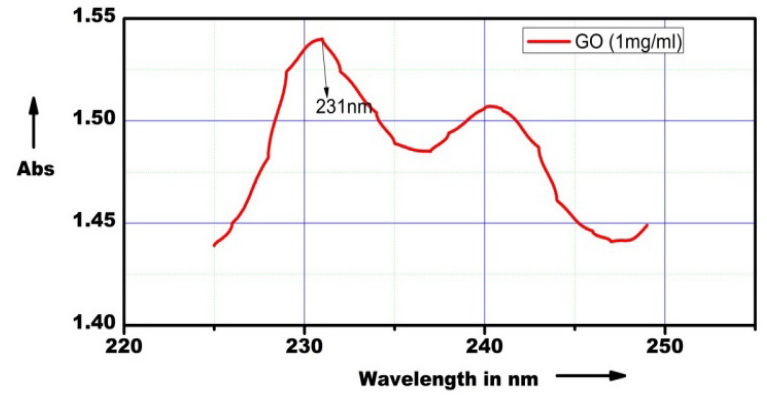

Figure 3. UV-Vis spectra of Graphene Oxide

\subsubsection{FT-IR Analysis}

FTIR gives information on molecular vibrations or more precisely on transition between vibrational and rotational energy levels in molecules. This information is of immerse help to organic chemists because it can be directly related to molecular structure. It has been extensively developed over the past decade and provides a number of advantages. Radiation containing all IR wavelengths (e.g., $4000-4000 \mathrm{~cm}^{-1)}$ is split into two beams. One beam is of fixed length, the other of variable length. There are a number of advantages to FT-IR methods. A data processing technique called Fourier transform turns this raw data into the desired result (the sample's spectrum): light output as a function of infrared wavelength (or equivalently, wave number). Since a monochromator is not used, the entire radiation range is passed through the sample simultaneously and much time is saved. FT-IR instrument can have very high resolution $\left(<0.001 \mathrm{~cm}^{-1}\right)$. In the present study graphene oxide was characterized using FT-IR

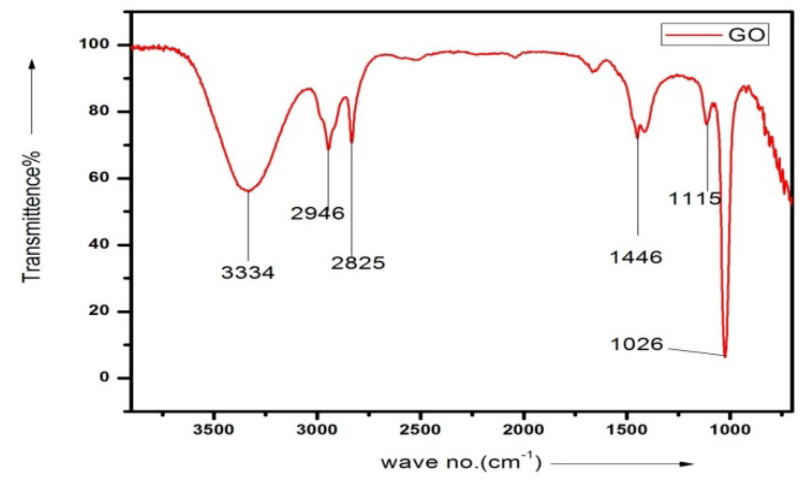

Figure 4. FT-IR spectra of GO dispersion
When we did FT-IR of GO dispersion, the presence of different types of oxygen functionalities in graphene oxide was confirmed at $3334 \mathrm{~cm}^{-1}$ (O-H stretching vibrations), at $1446 \mathrm{~cm}^{-1}$ (skeleton vibrations from unoxidized graphitic domains), at $1115 \mathrm{~cm}^{-1}$ (C-O stretching vibrations), and at $1026 \mathrm{~cm}^{-1}$ (C-O stretching vibrations).

\subsubsection{Scanning Electron Microscopy of Flakes}

The SEM micrograph of GO flakes is depicted in Fig. 5 at $10.0 \mathrm{kx}$ magnifications at a voltage of about $10 \mathrm{kV}$. This micrograph demonstrated that the prepared GO material was made up of many cavities, stacked and crumpled flakes closely associated with each other.

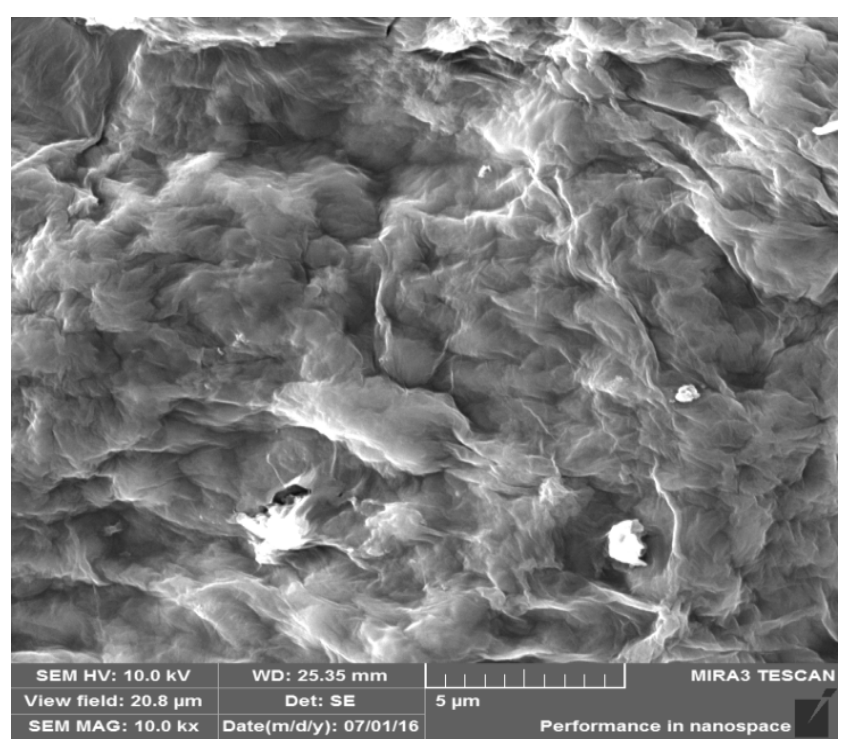

Figure 5. Scanning electron microscopy image of GO flakes

\subsubsection{EDX GO Flakes Analysis}

GO flakes was further exposed for EDX/EDS to know the elemental composition of surface of GO flakes. This study provides valuable information about the element composition of GO flakes. The EDX spectra fig 6(a,b) of GO flakes shows the presence of higher amount of carbon and oxygen. Which confirms that the membrane contains GO to its surface. Other elements were found as impurities on the surface of the membrane. The percentage presence of normal concentration and atomic concentration is given accordingly. 

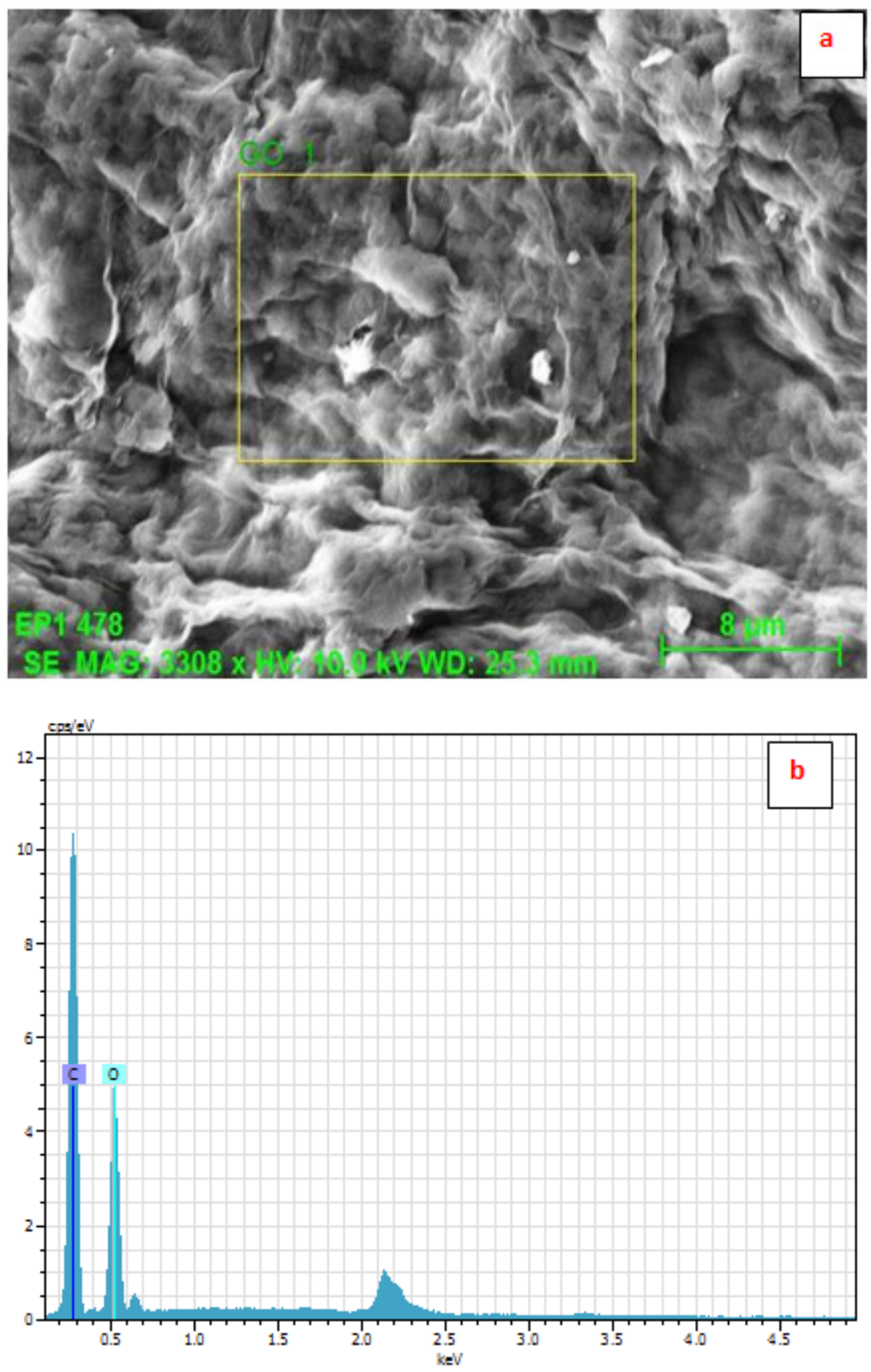

Figure 6. EDX image (a) and spectra (b) of GO flakes

Table 1. Elemental composition of GO flakes

\begin{tabular}{|c|c|c|}
\hline Element & Norm.C (Wt\%) & Atom.C (Wt \%) \\
\hline C & 56.39 & 63.27 \\
\hline O & 43.61 & 36.73 \\
\hline Total & 100 & 100 \\
\hline
\end{tabular}




\subsection{Coating of Nano Film Layer of Graphene Oxide on PCTE and EGG Membrane by}

\subsubsection{Various Methods}

Nano film layer of graphene oxide was coated on egg and polycarbonate track etch membrane (PCTE) by drop cast and vacuum filtration method.

\subsubsection{Surface Modification of Polycarbonate Track Etch \\ Membrane (PCTE) by Vacuum Filtration Method}

Polycarbonate Track-etch (PCTE) membranes of pour size $25 \mathrm{~nm}$ were coated by Graphene Oxide by vacuum filtration unit. Vacuum pressure of $15 \mathrm{Hg}$ was maintained. Membrane was coated uniformly.

\subsubsection{Surface Modification of Egg Membrane by Vacuum Filtration Method}

Egg membrane was coated by $1 \mathrm{mg} / \mathrm{ml}$ suspension of graphene oxide by vacuum filtration unit Vacuum pressure of $15 \mathrm{Hg}$ was maintained. Membrane was coated uniformly.

\subsubsection{Surface Modification of Polycarbonate Track Etch Membrane (PCTE) by Drop Cast Method}

Polycarbonate Track Etch Membranewas coated by one drop of $1 \mathrm{mg} / \mathrm{ml}$ suspension of graphene oxide by dropper. Membrane was coated uniformly.

\subsubsection{Surface Modification of Egg Membrane by Drop Cast Method}

Egg membrane was coated by one drop of $1 \mathrm{mg} / \mathrm{ml}$ suspension of graphene oxide by dropper. Membrane was coated uniformly.

\subsection{Characterization of Coated/Modified Membranes}

The characterization of modified membranes was done by inverted microscope, EDX and FT-IR study.

\subsubsection{Inverted Microscope}

The normal and GO coated PCTE membrane by vacuum filtration and drop casting method were put on petri dish (borosil) one by one and the micrograph was recorded at 40X. The micrograph in Fig.7 (a) depicts the clear surface of normal PCTE membrane with grayish colour while Fig.7 (b) shows the micrograph of GO coated PCTE membrane by vacuum filtration method and fig.7(c) depict GO coated PCTE membrane by drop cast method, it shows the golden brown colour of graphene oxide which is not reduced.

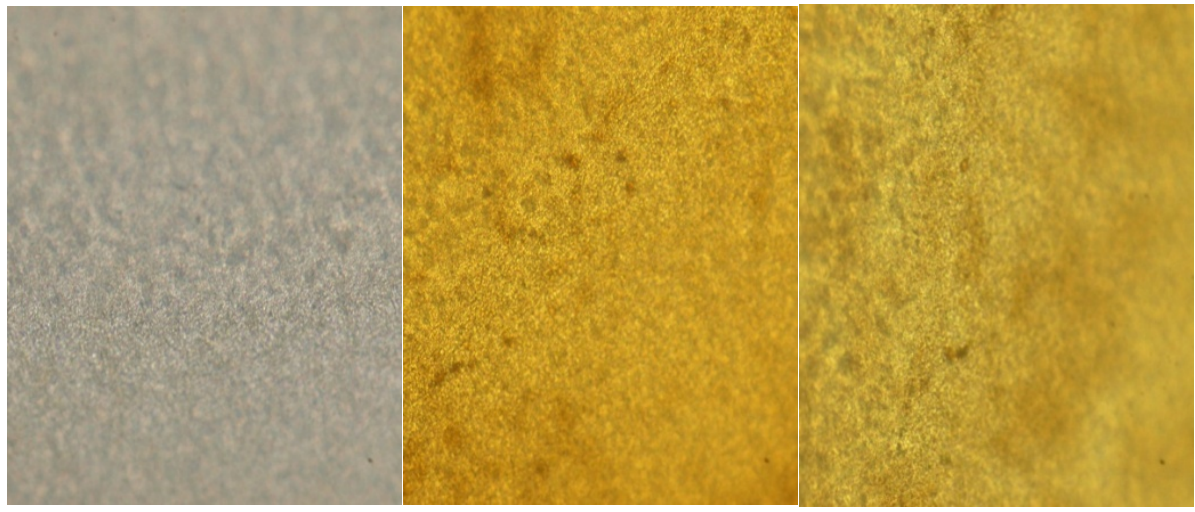

(a)

(b)

(c)

Figure 7. (a) :PCTE membrane micrograph by inverted microscope. (b) Inverted microscope micrograph of GO coated PCTE membrane by vacuum filtration method. (c) Inverted microscope micrograph of GO coated PCTE membrane by drop cast method.

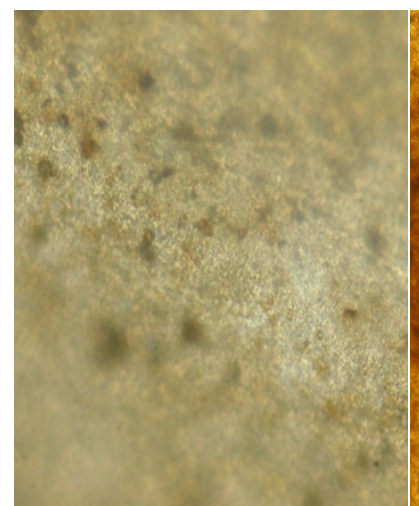

(a)

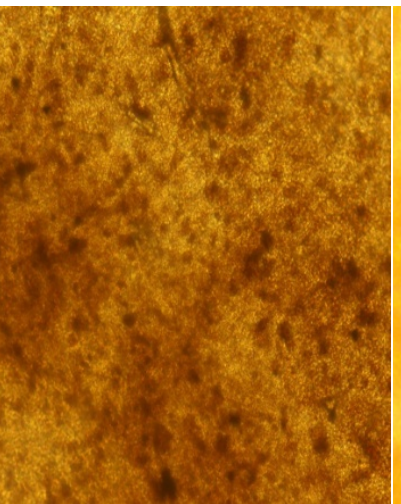

(b)

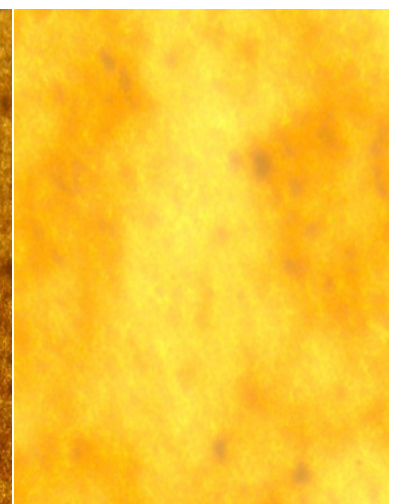

(c)

Figure 8. (a) Egg membrane micrograph by inverted microscope. (b) Inverted microscope micrograph of GO coated Egg membrane by vacuum filtration method. (c) Inverted microscope micrograph of GO coated Egg membrane by drop cast method. 
The normal and GO coated Egg membrane by vacuum filtration and drop casting method were put on petri dish (borosil) one by one and the micrograph was recorded at 40X. The micrograph in Fig. 8(a) depicts the clear surface of normal Egg membrane with grayish colour while Fig.8(b) shows the micrograph of GO coated Egg membrane by vacuum filtration method and Fig. 8 (c) depict GO coated Egg membrane by drop cast method, it shows the golden brown colour of graphene oxidewhich is not reduced.

\subsubsection{FE-SEM Imaging}

The FE-SEM micrograph of coated Nano film on various membranes by various methods is depicted in Fig. 9 at $10.0 \mathrm{kx}$ magnifications at a voltage of $10 \mathrm{kV}$.

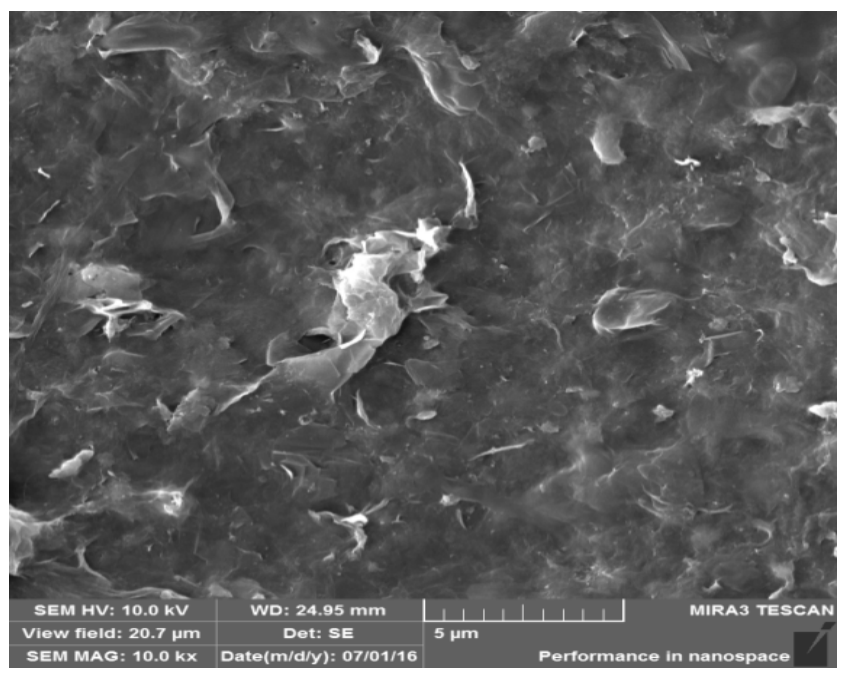

(a)

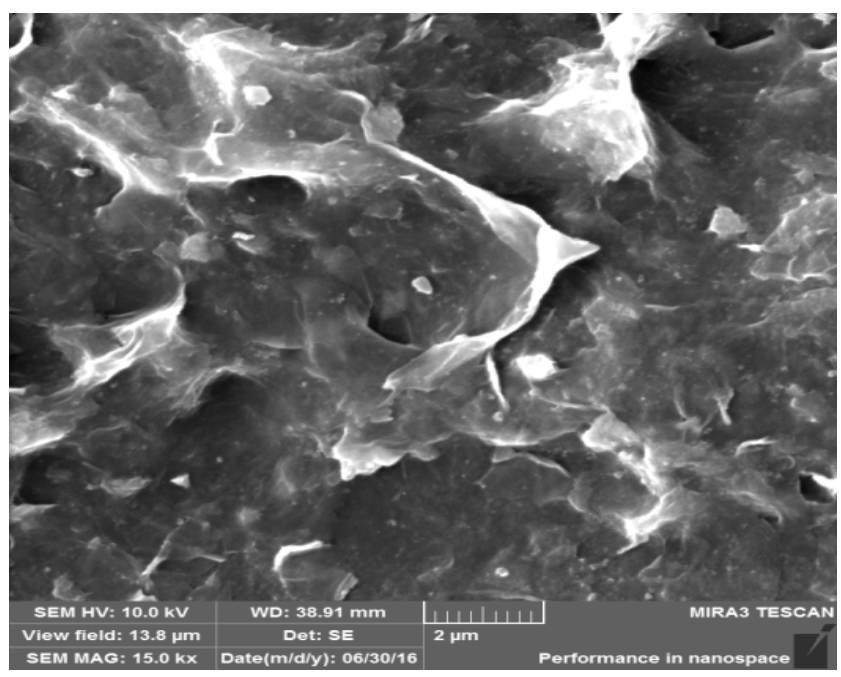

(b)

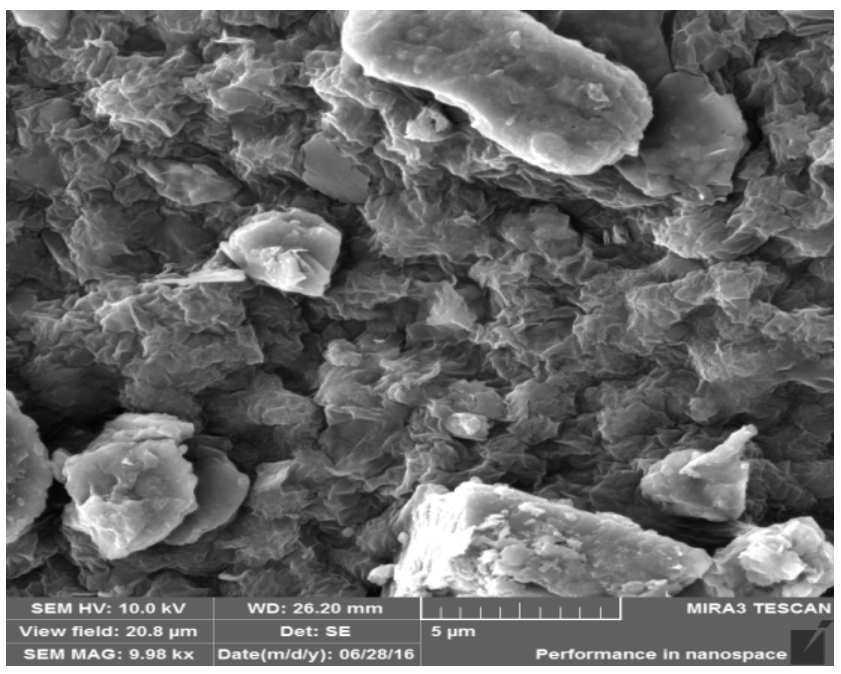

(c)

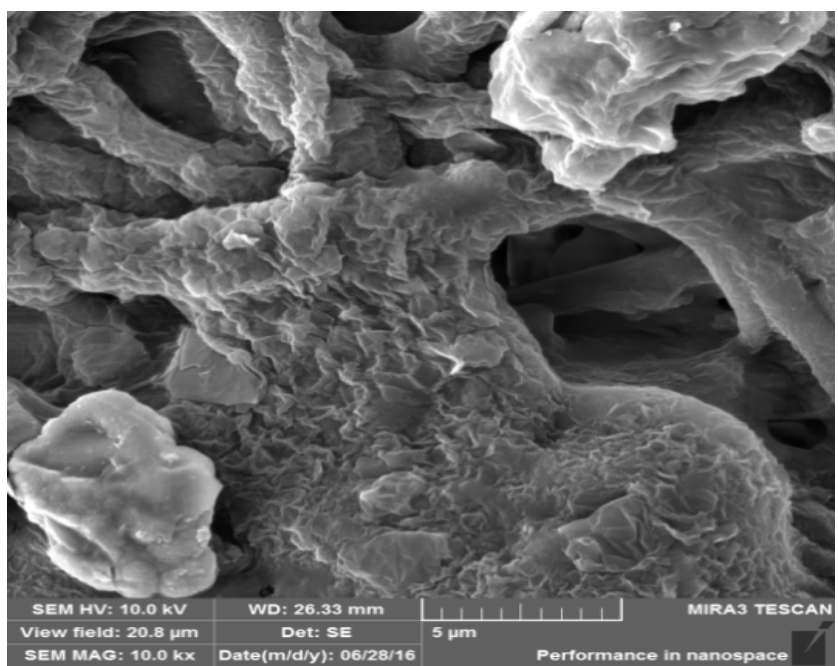

(d)

Figure 9. (a) FE-SEM image of GO coated PCTE membrane by Vacuum filtration method (b) FE-SEM image of GO coated PCTE membrane by drop cast method (c) FE-SEM image of GO coated Egg membrane by Vacuum filtration method (d) ) FE-SEM image of GO coated Egg membrane by drop cast method.

This micrograph demonstrated that fabrication of thin layer graphene oxide Nano film on PCTE membrane by vacuum filtration method is the best method of fabrication because of its uniform coating comparing to other methods as well as we also got the conformation that egg membrane can be used for the fabrication of graphene oxide thin film which can reduce the cost of buying artificial membrane up to manifold. All micrographs shows some common characteristic that is the prepared GO material was made up of many cavities, stacked and crumpled flakes closely associated with each other. 


\subsubsection{EDX coated GO Membranes by Various Method Analyses}

Coated GO on various membrane by various techniques was further exposed for EDX/EDS to know the elemental composition. This study provides valuable information about the element composition of GO on various membrane. The EDX spectra fig.10 (a,b,c) shows the presence of higher amount of carbon and oxygen. Which confirms that the membrane contains GO to its surface. Other elements were found as impurities on the surface of the membrane. The percentage presence of normal concentration and atomic concentration is given accordingly.
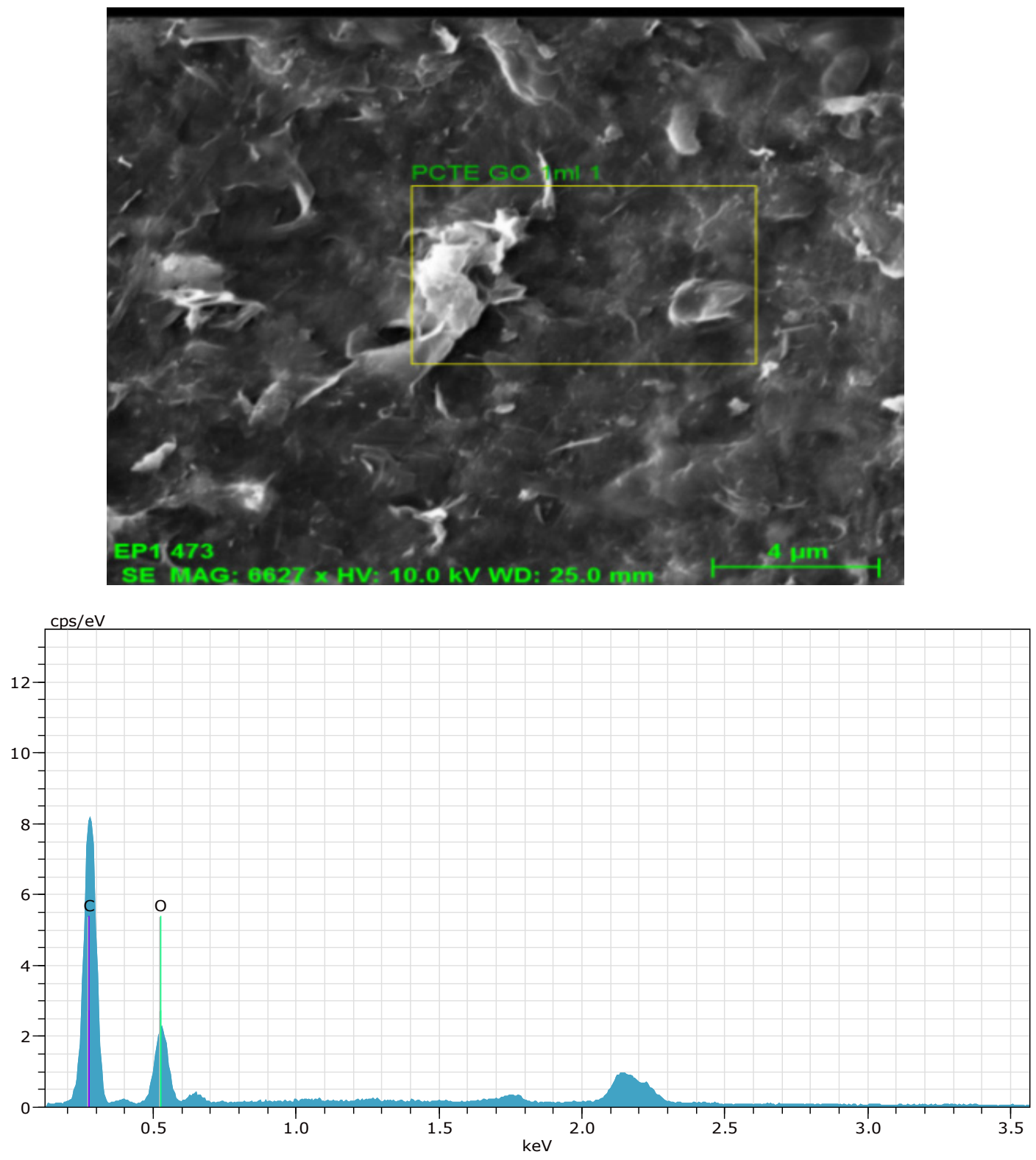

\section{El AN Series unn. C nom. C Atom. C Error (1 Sigma) [wt.\%] [wt.\%] [at.\%] [wt.\%]

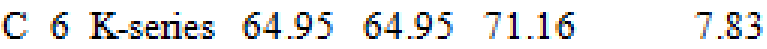 \\ O 8 K-series $35.05 \quad 35.05 \quad 28.84 \quad 4.83$}

Total: $100.00 \quad 100.00 \quad 100.00$ 

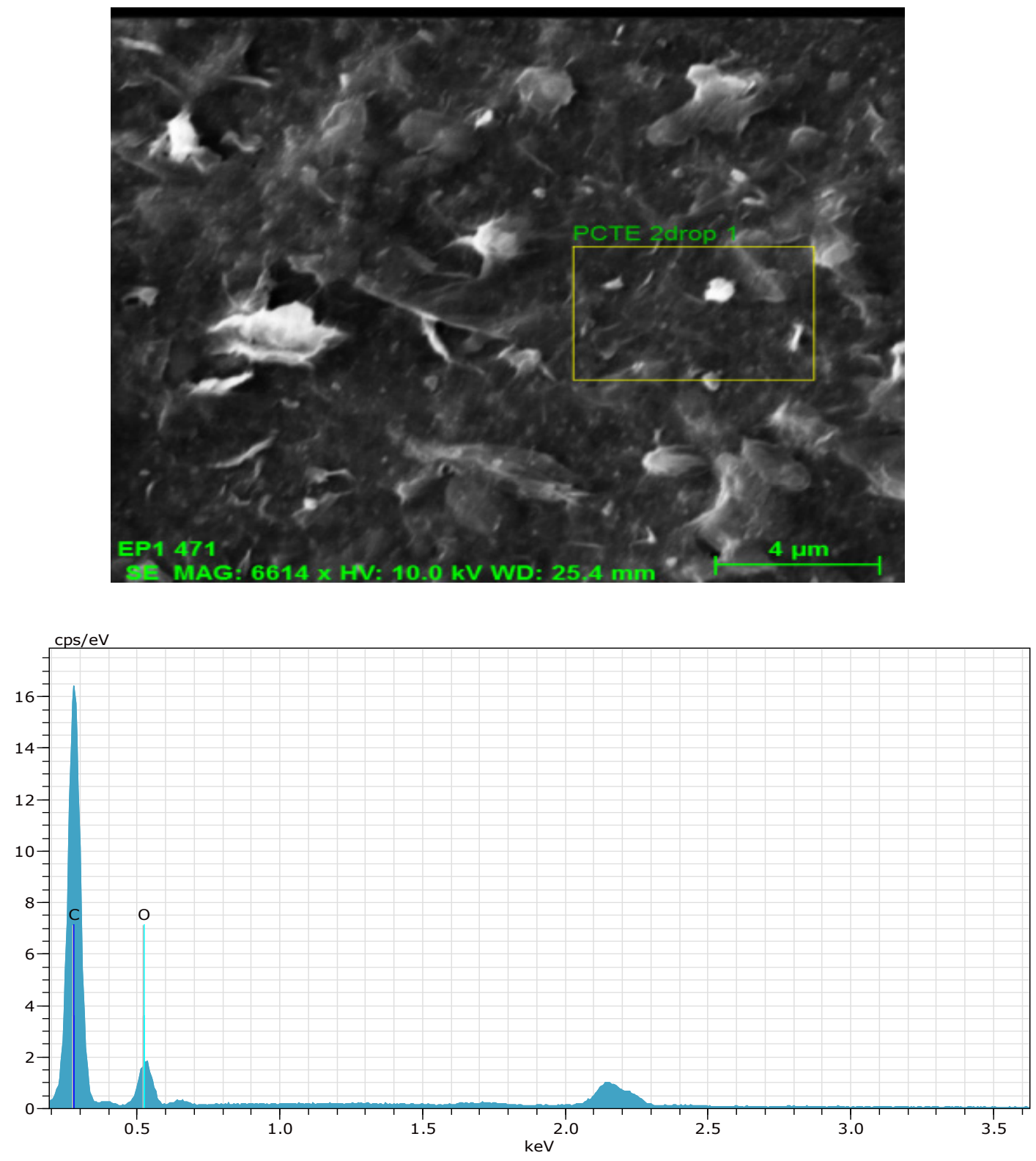
El AN Series unn. C norm. C Atom. C Error (1 Sigma) [wt.\%] [wt.\%] [at.\%] [wt.\%]

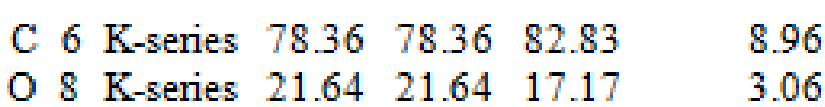

Total: 100.00100 .00100 .00

(b) 

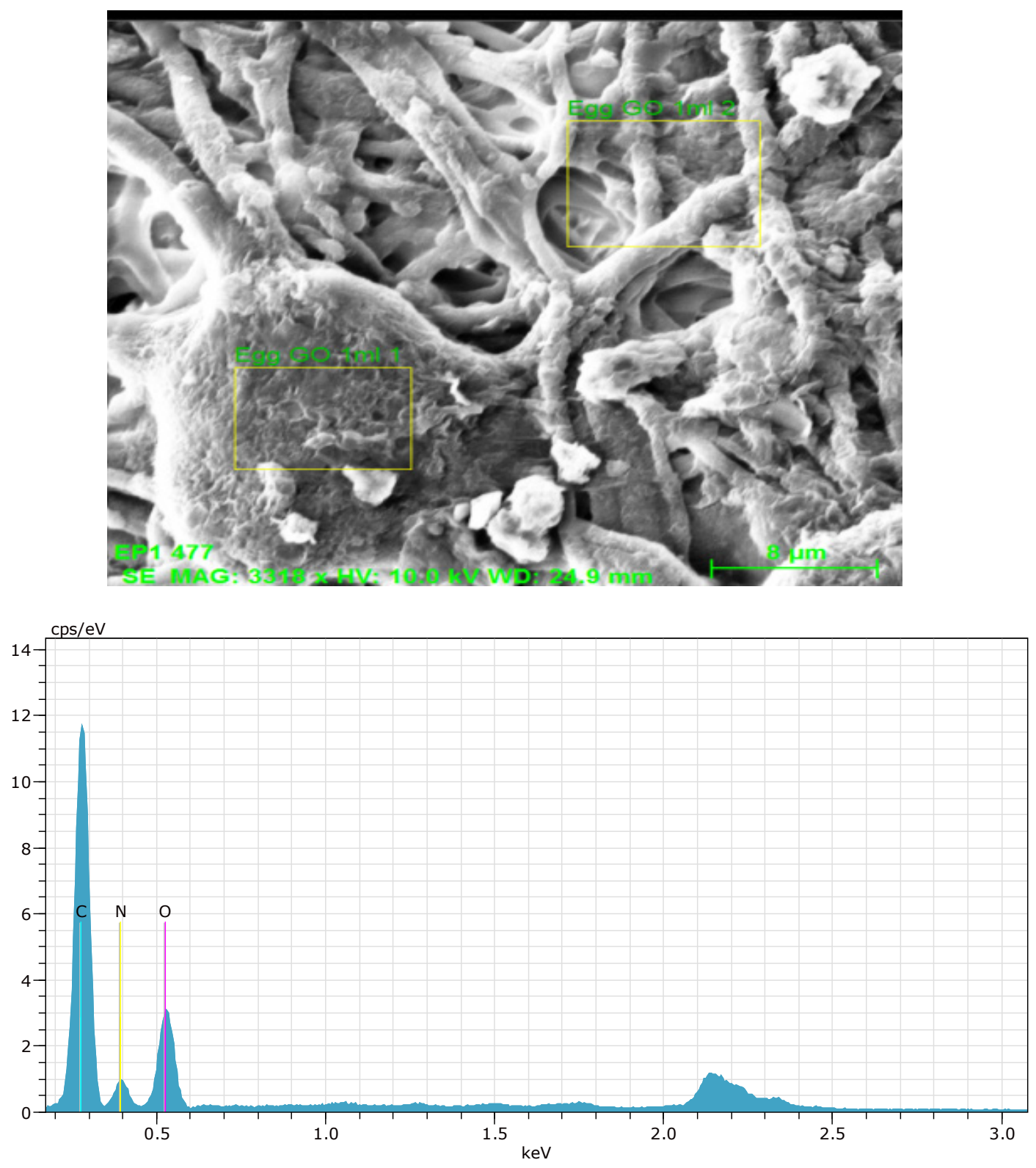

\section{El AN Series unn. C nom. C Atom. C Error (1 Sigma) [wt.\%] [wt.\%] [at.\%] [wt.\%]

$\begin{array}{lllllll}\text { C } & 6 & \text { K-series } & 52.15 & 52.15 & 58.02 & 6.12 \\ \text { O } & 8 & \text { K-series } & 30.88 & 30.88 & 25.79 & 4.08 \\ \text { N } 7 & \text { K-series } & 16.97 & 16.97 & 16.19 & 2.72\end{array}$

Total: 100.00100 .00100 .00

(c)

Figure 10. (a) Edx analysis of GO coated PCTE membrane by vacuum filtration (b) )Edx analysis of GO coated PCTE membrane by drop cast method (c) )Edx analysis of GO coated egg membrane by vacuum filtration. 


\subsubsection{FT-IR analysis of Coated GO Membranes by Various Methods}

Coated GO on various membrane by various techniques was further exposed for FT-IR analysis to know the functional groups. The FT-IR spectra of coated GO membrane by various methods along with its peak are shown in fig.11(a, b, c)

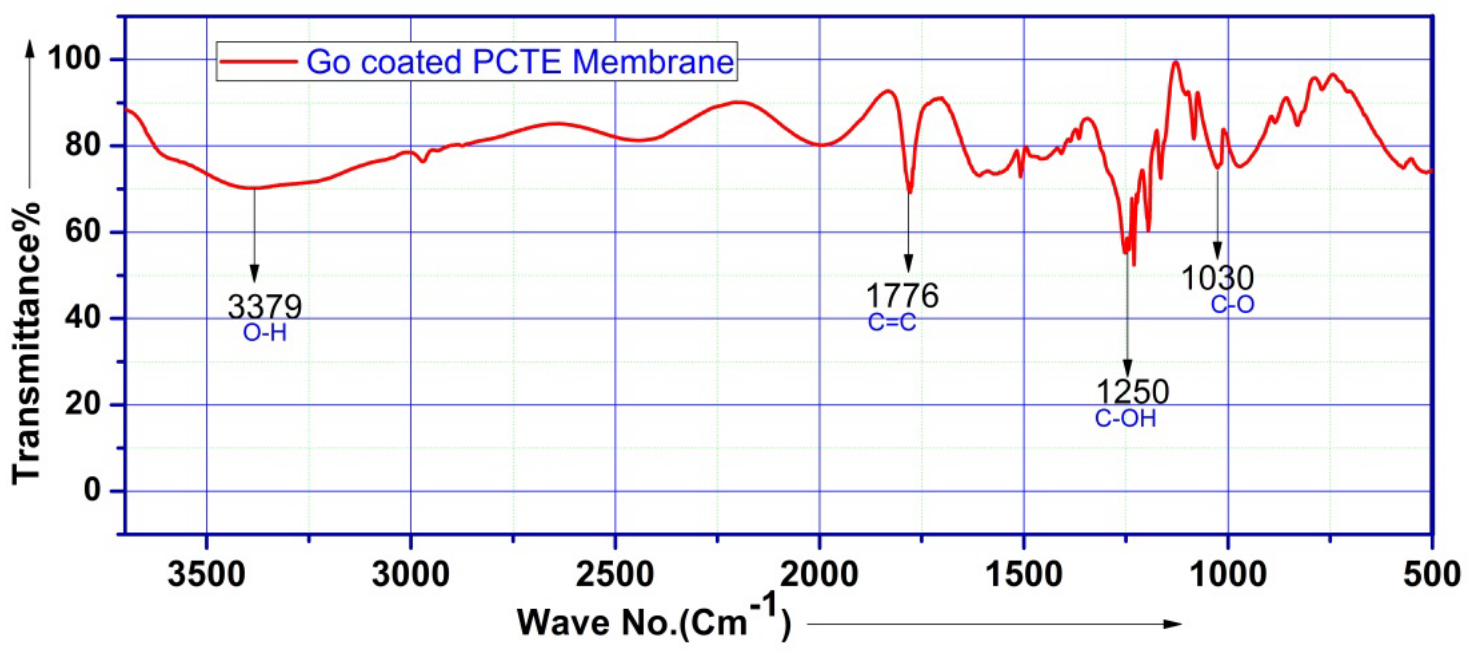

(a)

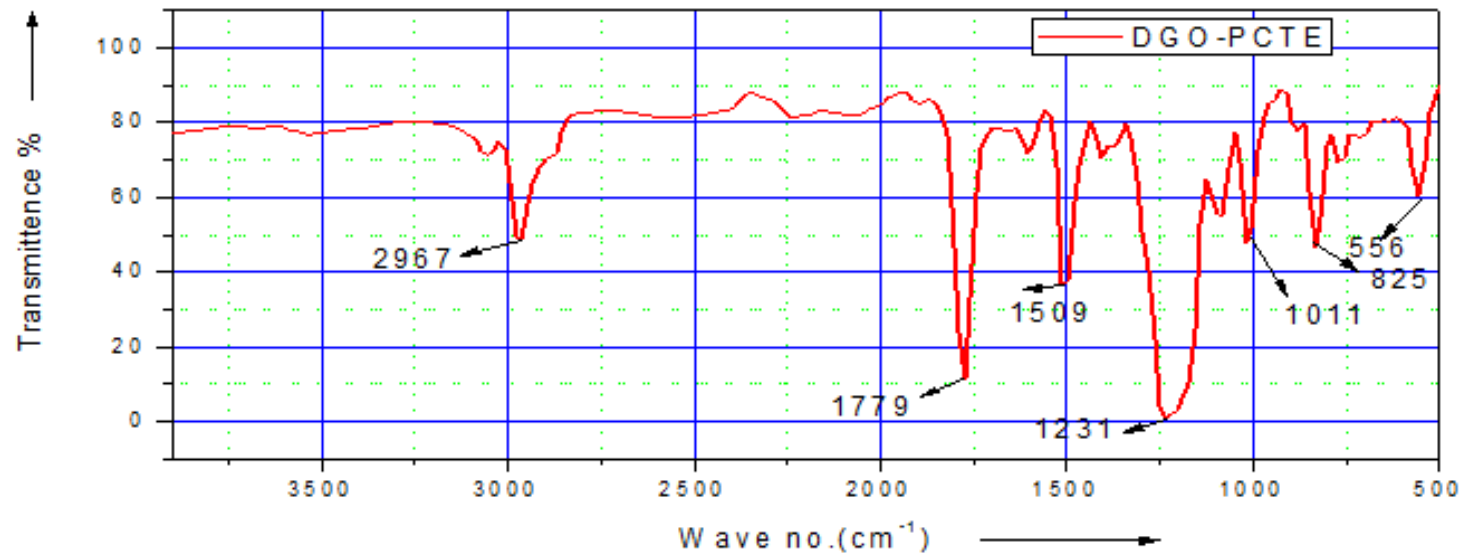

(b)

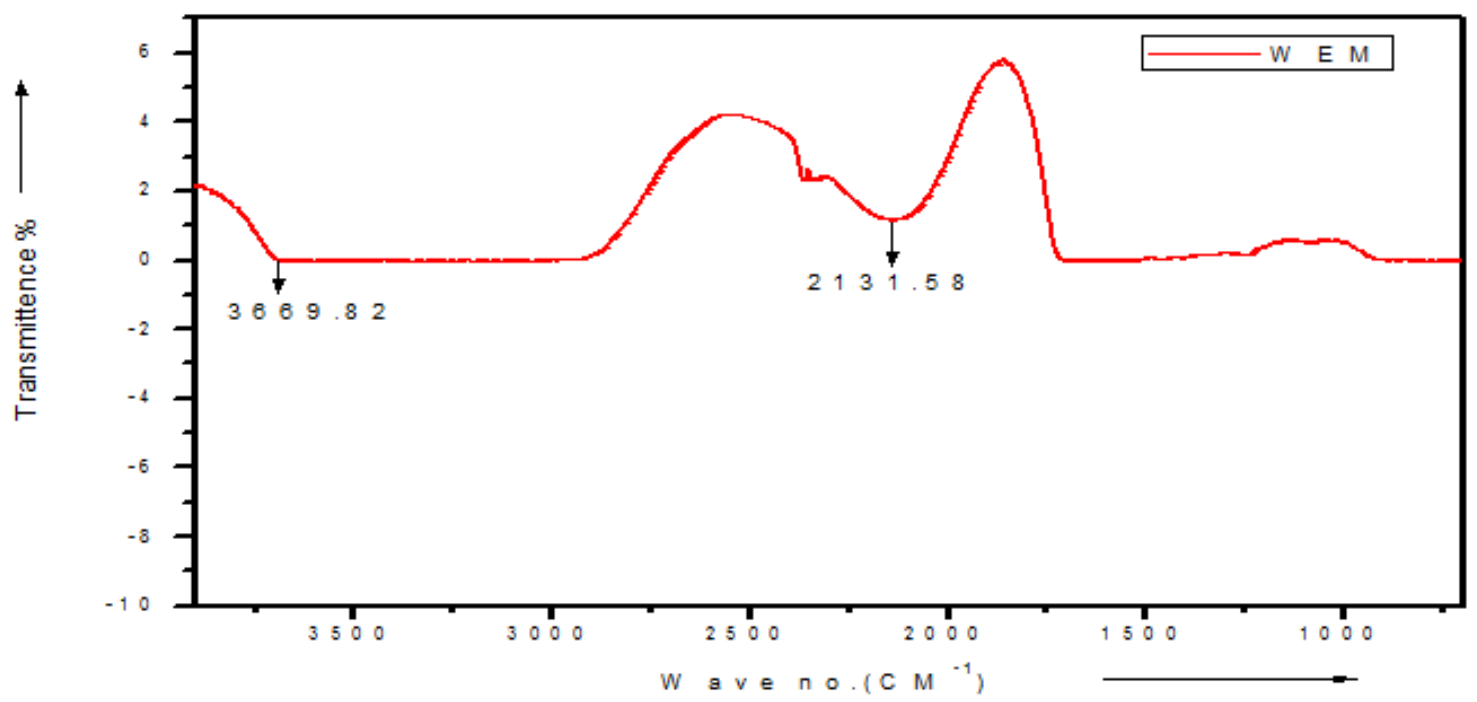

(c) 


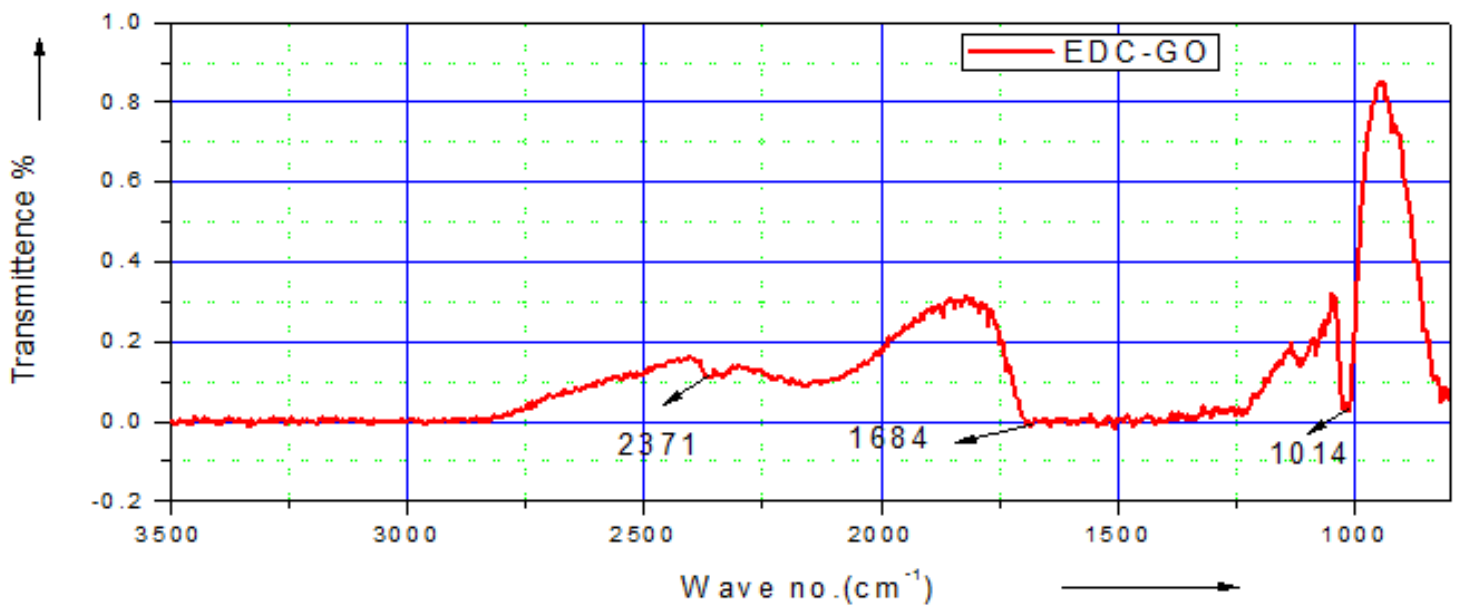

(d)

Figure 11. (a) FT-IR spectra of GO coated PCTE membrane by Vacuum filtration method (b) FT-IR spectra of GO coated PCTE membrane by drop cast method (c) FT-IR spectra of GO coated Egg membrane by drop cast method (d) ) FT-IR spectra of GO coated Egg membrane by drop cast method.

From the above FT-IR peaks we can clearly see the peaks starting from 3669.82 to 556 wave number $\left(\mathrm{cm}^{-1}\right)$ which indicates the presence various functional groups such as $\mathrm{C}=\mathrm{O}(1030), \mathrm{C}-\mathrm{OH}(1250), \mathrm{C}=\mathrm{O}(1776), \mathrm{O}-\mathrm{H}$ stretching $(3379), \mathrm{C}-\mathrm{H}$ stretching(2967), $\mathrm{C}=\mathrm{O} \quad$ stretching (1779), $\mathrm{C}=\mathrm{C}$ bonding (1509), $\mathrm{C}-\mathrm{H} \quad$ asymmetrical stretching (1231), $\mathrm{C}-\mathrm{F}$ stretching(1011), $\mathrm{C}-\mathrm{Br}$ stretching(556), $\mathrm{O}-\mathrm{H}$ stretching (3669.82), $\mathrm{C} \equiv \mathrm{C}$ stretching(2131.58), $\mathrm{C}-\mathrm{H}$ stretching(2871), $\mathrm{C}=\mathrm{O}$ amide stretching(1684), C-F stretching (1014) wave number $\left(\mathrm{cm}^{-1}\right)$. The graphene oxide coated membrane shows the presence of $\mathrm{C}=\mathrm{O}$ stretch from 1000 to 1300 wave number $\left(\mathrm{cm}^{-1}\right)$ which conforms the presence of graphene oxide on membrane .

\subsection{Measurement of Potential Across Different Membrane}

Potential across coated and simple (uncoated) egg and PCTE membrane was taken.

\subsubsection{Measurement of Potential by $\mathrm{NaCl}$ Across Different Membrane}

$1 \mathrm{M} \mathrm{NaCl}$ was filled on micro tube with attached membranes (above) and $0.1 \mathrm{M} \mathrm{NaCl}$ was filled full on test-tube (below), in it micro tube with attached membrane was placed in such a way that its membrane touches the solution of test-tube one electrode was then fixed at micro tube and another electrode was fixed at test tube and then consecutive potential measurement was taken at a time interval of ten second for 1 minute.

Table 2. This table along with graph shows (a) potential across PCTE membrane (b) potential cross egg membrane (c) potential across coated PCTE membrane (d) potential across coated egg membrane.

\begin{tabular}{|c|c|c|}
\hline \multicolumn{3}{|c|}{ PCTE membrane NaCl } \\
\hline SL.NO & $\begin{array}{c}\text { TIME } \\
(\text { SEC. })\end{array}$ & $\begin{array}{c}\text { POTENTIAL } \\
(\mathrm{mV})\end{array}$ \\
\hline 1 & 0 & 30.2 \\
\hline 2 & 10 & 30.1 \\
\hline 3 & 20 & 30.0 \\
\hline 4 & 30 & 29.9 \\
\hline 5 & 40 & 29.8 \\
\hline 6 & 50 & 29.7 \\
\hline 7 & 60 & 29.7 \\
\hline
\end{tabular}

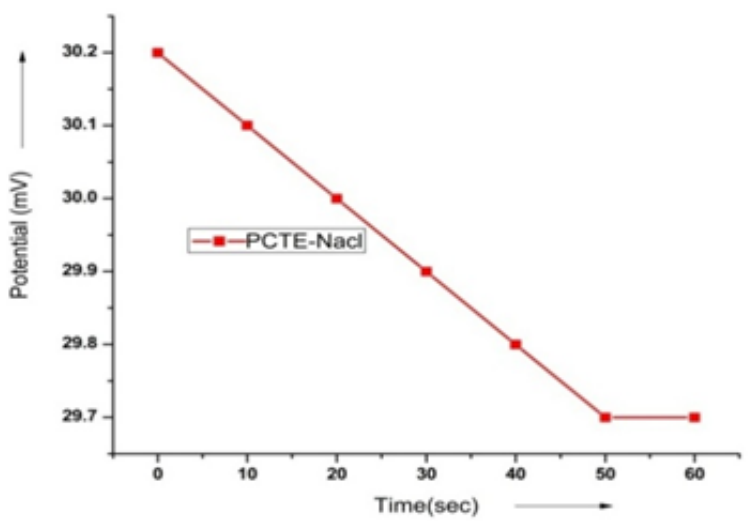




\begin{tabular}{|c|c|c|}
\hline \multicolumn{3}{|c|}{ Egg Membrane NaCl } \\
\hline SL.NO & $\begin{array}{l}\text { TIME } \\
\text { (SEC.) }\end{array}$ & $\begin{array}{l}\text { POTEN } \\
\text { TIAL } \\
(\mathrm{mV})\end{array}$ \\
\hline 1 & 0 & 38.9 \\
\hline 2 & 10 & 38.5 \\
\hline 3 & 20 & 38.1 \\
\hline 4 & 30 & 37.6 \\
\hline 5 & 40 & 37.2 \\
\hline 6 & 50 & 36.4 \\
\hline 7 & 60 & 30.0 \\
\hline
\end{tabular}

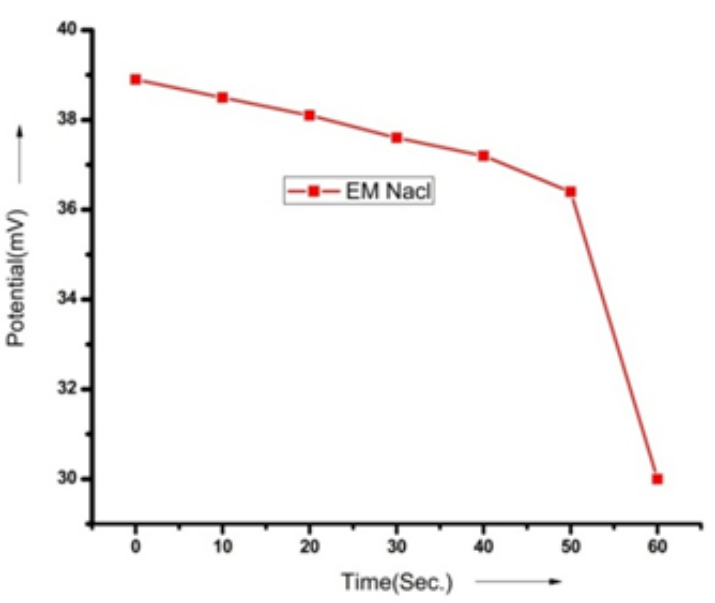

\begin{tabular}{|c|c|c|}
\hline \multicolumn{3}{|c|}{ PCTE GO NaCl } \\
\hline SL.NO & $\begin{array}{c}\text { TIME } \\
(\text { SEC. })\end{array}$ & $\begin{array}{c}\text { POTENTIAL } \\
(\mathrm{mV})\end{array}$ \\
\hline 1 & 0 & 50.2 \\
\hline 2 & 10 & 50.0 \\
\hline 3 & 20 & 49.6 \\
\hline 4 & 30 & 49.4 \\
\hline 5 & 40 & 49.2 \\
\hline 6 & 50 & 49.0 \\
\hline 7 & 60 & 48.8 \\
\hline
\end{tabular}

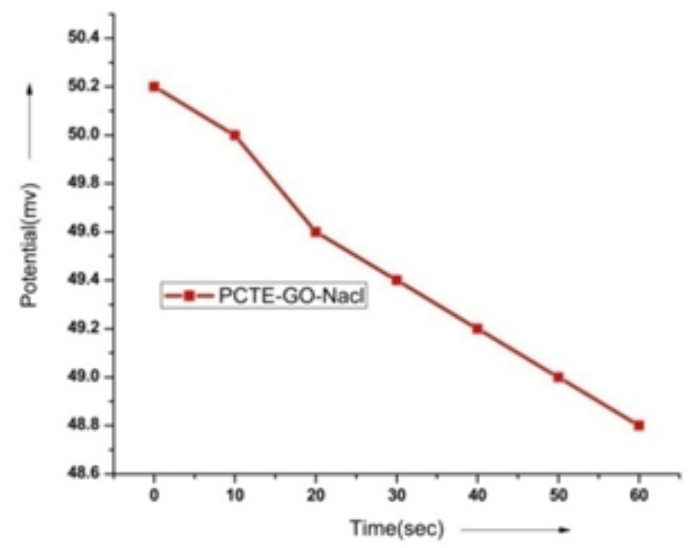

\begin{tabular}{|c|c|c|}
\hline \multicolumn{3}{|c|}{ EGG GO NaCl } \\
\hline SL.NO & $\begin{array}{c}\text { TIME } \\
(\text { SEC. })\end{array}$ & $\begin{array}{c}\text { POTENTIAL } \\
(\mathrm{mV})\end{array}$ \\
\hline 1 & 0 & 33.3 \\
\hline 2 & 10 & 33.2 \\
\hline 3 & 20 & 33.1 \\
\hline 4 & 30 & 33.0 \\
\hline 5 & 40 & 32.9 \\
\hline 6 & 50 & 32.8 \\
\hline 7 & 60 & 32.7 \\
\hline
\end{tabular}

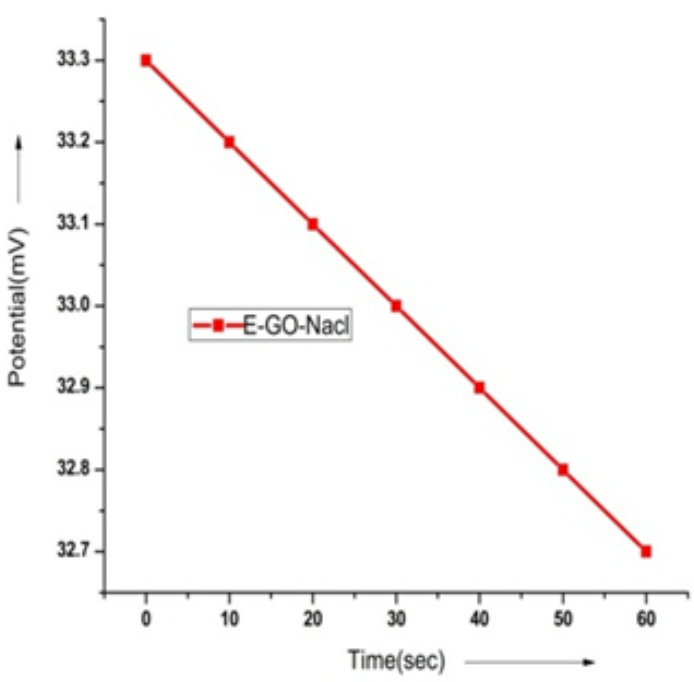

3.5.2. Measurement of Potential by $\mathrm{MgCl}_{2}$ Across Different Membrane

$1 \mathrm{M} \mathrm{MgCl}_{2}$ was filled on micro tube with attached membranes (above) and $0.1 \mathrm{M} \mathrm{MgCl}_{2}$ was filled full on test-tube (below), in it micro tube with attached membrane was placed in such a way that its membrane touches the solution of test-tube one electrode was then fixed at micro tube and another electrode was fixed at test tube and then consecutive potential measurement was taken at a time interval of ten second for 1 minute. 
Table 3. These table and graph shows (a) potential across PCTE membrane (b) potential cross egg membrane (c) potential across coated PCTE membrane $(\mathrm{d})$ potential across coated egg membrane $(\mathrm{e})$ comparison of potential graphs across different membrane by different techniques graphs $[B 1$ :

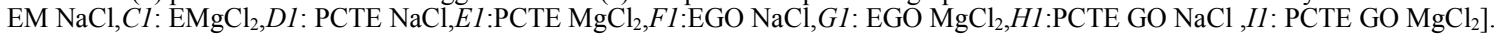

\begin{tabular}{|c|c|c|}
\hline \multicolumn{3}{|c|}{ PCTE MEMBRANE $\mathrm{MgCl}_{2}$} \\
\hline SL.NO & $\begin{array}{c}\text { TIME } \\
\text { (SEC.) }\end{array}$ & $\begin{array}{c}\text { POTENTIAL } \\
(\mathrm{mV})\end{array}$ \\
\hline 1 & 0 & 29.1 \\
\hline 2 & 10 & 28.7 \\
\hline 3 & 20 & 28.3 \\
\hline 4 & 30 & 28.0 \\
\hline 5 & 40 & 27.6 \\
\hline 6 & 50 & 27.2 \\
\hline 7 & 60 & 26.8 \\
\hline
\end{tabular}

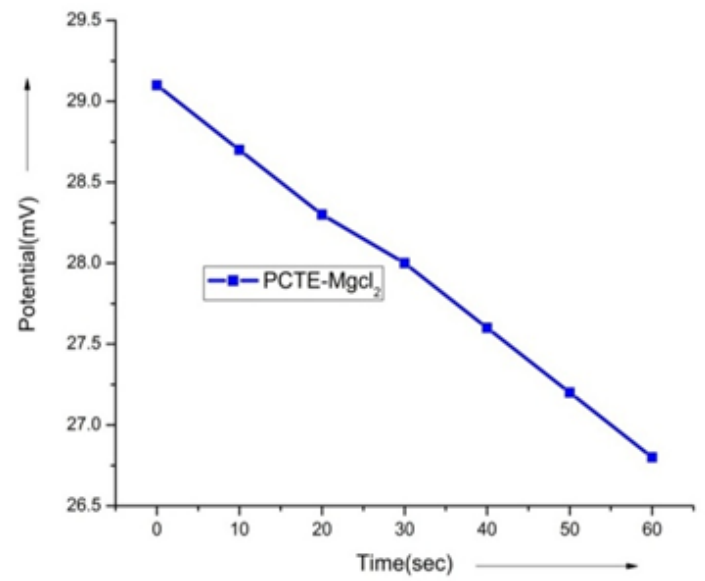

\begin{tabular}{|c|c|c|}
\hline \multicolumn{3}{|c|}{ EGG MEMBRANE $\mathrm{MgCl}_{2}$} \\
\hline SL.NO & $\begin{array}{c}\text { TIME } \\
(\text { SEC })\end{array}$ & $\begin{array}{c}\text { POTENTIAL } \\
(\mathrm{mV})\end{array}$ \\
\hline 1 & 0 & 11.7 \\
\hline 2 & 10 & 11.5 \\
\hline 3 & 20 & 11.3 \\
\hline 4 & 30 & 10.9 \\
\hline 5 & 40 & 10.8 \\
\hline 6 & 50 & 10.8 \\
\hline 7 & 60 & 10.7 \\
\hline
\end{tabular}

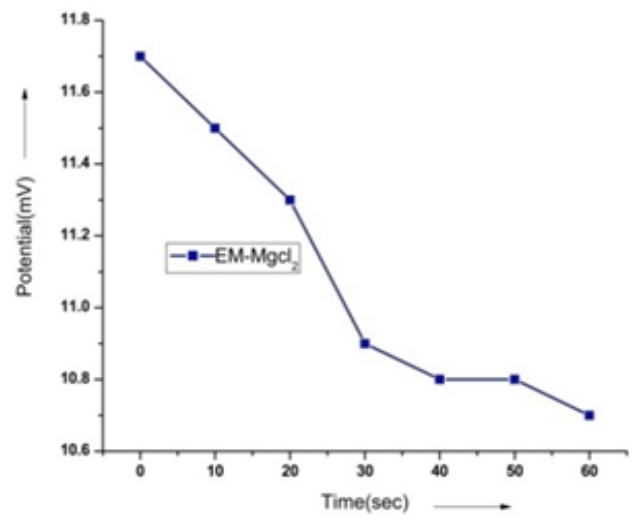

\begin{tabular}{|c|c|c|}
\hline \multicolumn{3}{|c|}{ PCTE GO MgC12 } \\
\hline SL.NO & $\begin{array}{c}\text { TIME } \\
(\text { SEC) }\end{array}$ & $\begin{array}{c}\text { POTENTIAL } \\
(\mathrm{mV})\end{array}$ \\
\hline 1 & 0 & 28.0 \\
\hline 2 & 10 & 27.4 \\
\hline 3 & 20 & 26.8 \\
\hline 4 & 30 & 26.2 \\
\hline 5 & 40 & 25.6 \\
\hline 6 & 50 & 25.4 \\
\hline 7 & 60 & 25.2 \\
\hline
\end{tabular}

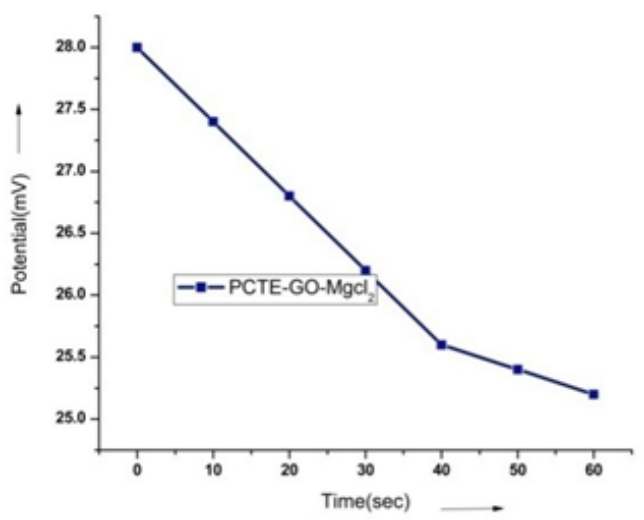




\begin{tabular}{|c|c|c|}
\hline \multicolumn{3}{|c|}{ EGG Go $\mathrm{MgCl}_{2}$} \\
\hline SL.NO & $\begin{array}{c}\text { TIME } \\
(\text { SEC) }\end{array}$ & $\begin{array}{c}\text { POTENTIAL } \\
(\mathrm{mV})\end{array}$ \\
\hline 1 & 0 & 18.2 \\
\hline 2 & 10 & 17.8 \\
\hline 3 & 20 & 17.4 \\
\hline 4 & 30 & 17.0 \\
\hline 5 & 40 & 16.8 \\
\hline 6 & 50 & 16.4 \\
\hline 7 & 60 & 16.0 \\
\hline
\end{tabular}
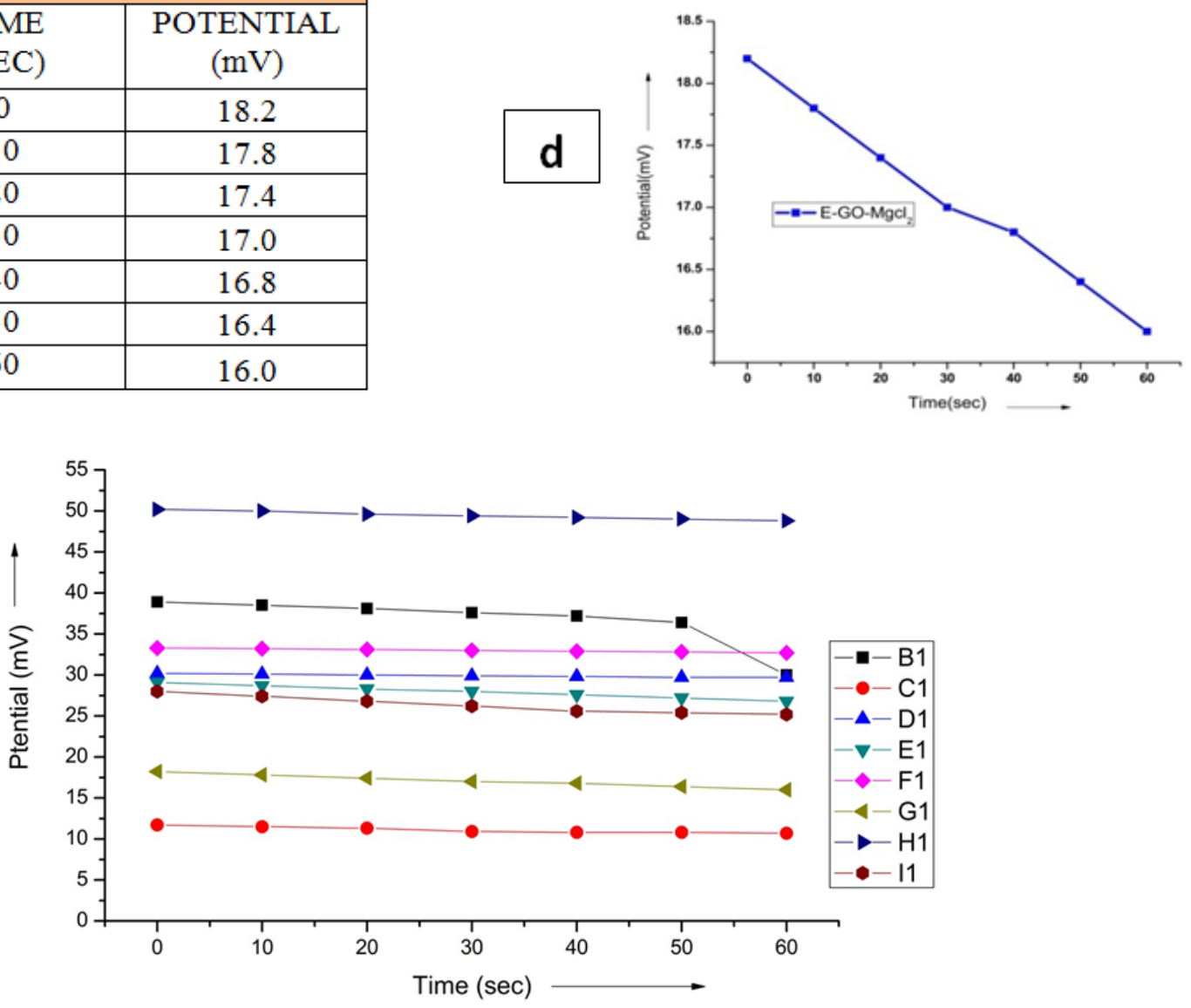

From the above graph we can see that there is clear cut downfall in potential with respect to time. Out of all GO coated membrane mentioned above highest potential was shown by PCTE membrane and lowest potential was shown by egg membrane. As well as monovalent solution that is $\mathrm{NaCl}$ shows higher potential as compared to divalent solution that is $\mathrm{MgCl}_{2}$. At last but not the least potential of GO coated membrane is highest as compared to simple membrane.

From the above all results we can conclude that Vacuum filtration method is the best suited method for GO coating and it's quite interesting to note from the above result that Egg membrane also can be used for the fabrication of thin layer GO nano film which is highly cost effective as compared to artificial membrane like PCTE as well as we can expect a huge scope of egg membrane for GO fabrication for upcoming future.

\section{Conclusions}

In the present study, preparation, characterization of graphene oxide and the coating of PCTE as well as membrane extracted from egg shell with graphene oxide are processed. Furthermore, potential gradient of membranes was achieved through instrumentation. The objectives of the work were to produce graphene oxide for Coating of Nano-Film layer on membrane by different methods, its characterization and potential check of coated as well as non-coated membrane.

Graphene oxide was prepared with the modified Hummer's method. After the production of graphene oxide flakes $1 \mathrm{mg} / \mathrm{ml}$ dispersion was made. Then obtained GO flakes and GO dispersion was subjected for characterization by FE-SEM, EDX, UV-Vis spectrophotometry and FT-IR to check our prepared GO quality or to conform that our GO is prepared properly. After characterization we have seen that our GO had fulfilled all parameters what a proper GO should have. Then this GO was used for coating of different membrane by different methods.

These methods include Nano film layer of graphene oxide coated on egg and polycarbonate track etch membrane (PCTE) by drop cast and vacuum filtration method. Four polycarbonate membranes each of $50 \mathrm{~nm}$ pore size and four egg membranes were modified by 
coating it with 1 drop as well as $1 \mathrm{ml}$ of $1 \mathrm{mg} / \mathrm{ml}$ concentration of Graphene oxide for drop cast and vacuum filtration method respectively. Then membranes were kept for drying at room temperature and after drying the membranes especially the egg membrane were kept at refrigerator for storing.

The GO coated PCTE and Egg membrane was characterized by the help of inverted microscopy, UV-Visible spectrophotometry, Fourier Transform Infrared spectroscopy (FT-IR), Energy Dispersive Spectroscopy (EDS), and Scanning Electron Microscopy (SEM) and based on the characterization we got to know that vacuum filtration method is the best suited method for coating thin layer nano film on membranes. Most interesting part was to note that egg membrane could also be used for coating of thin layer GO nano film on it, which can reduce cost of buying artificial membrane up to many folds.

After the characterization of coated membrane is done then we check the potential across different membrane to know which membrane has the highest and which has a lowest potential. And for that we first made the silver chloride electrode . Then we made a set up for checking the potential across different membrane .From the potential measurement across different membrane we saw that there is clear cut downfall in potential with respect to time. Out of all GO coated membrane highest potential was shown by PCTE membrane and lowest potential was shown by egg membrane. As well as monovalent solution that is $\mathrm{NaCl}$ shows higher potential as compared to divalent solution that is $\mathrm{MgCl}_{2}$.At last but not the least potential of $\mathrm{GO}$ coated membrane was highest as compared to simple membrane.

\section{Acknowledgements}

The preparation/making process of graphene oxide and characterization was done as per the plan in the 'Bio-Nanotechnology and Nano biosensor Research Laboratory', College of Basic Sciences and Humanities, G.B Pant University of Agriculture and Technology, Pantnagar-263145.This work was partly performed at the Material Evaluation Laboratory of CSIR-CBRI, Roorkee (IIT Roorkee).

\section{REFERENCES}

[1] Singh, P. R. 2011. Prospects of nanobiomaterials for biosensing. International journal of electrochemistry. 10: 125487.
[2] Alagarasi, A. 2000. Introduction to nanomaterials. A John Wlley \& sons, Inc. publication.

[3] Kohane, D.S. and Langer, R. 2010. Biocompatibility and drug delivery systems. Chemical Science. 1(4): 441-446.

[4] Feng, J. J., Yan-Yan, S., Xiao-Miao, F., Shrestha, N. K. and Wisitruangsakul, N. 2013. Biocompatible functional nanomaterials: synthesis, properties, and applications. Journal of Nanomaterials. Article ID-385939. pp-1.

[5] Liu, C., Yu, Z., Neff, D., Zhamu, A. and Jang, B. Z. 2010. Graphene-based supercapacitor with an ultrahigh energy density. Nano letters. 10(12): 4863-4868.

[6] Geim, A. K. and Novoselov, K. S. 2007. The rise of graphene. Nature materials. 6(3): 183-191.

[7] Luz, R. A., Iost, R. M. and Crespilho, F. N. 2013. Nanomaterials for biosensors and implantable biodevices. Nanobioelectrochemistry. Springer, Berlin, Heidelberg. pp. 27-48.

[8] Gray, J. R. 2004. "Conductivity Analyzers and Their Application". In Down, Lehr R.D, J.H. Environmental Instrumentation and Analysis Handbook. Wiley. pp. 491-510.

[9] Novoselov, K. S., Geim, A. K., Morozov, S. V., Jiang, D., Zhang, Y., Dubonos, S. V. and Firsov, A. A. 2004. Electric field effect in atomically thin carbon films. Science. 306(5696): 666-669.

[10] Shao, G., Lu, Y., Wu, F., Yang, C., Zeng, F. and Wu, Q. 2012. Graphene oxide: the mechanisms of oxidation and exfoliation. Journal of materials science. 47(10): 4400-4409.

[11] Shahriary, L. and Athawale, A. A. 2014. Graphene oxide synthesized by using modified hummers approach. Int $J$ Renew Energy Environ Eng. 2: 58-63.

[12] Yan Y Chen, Z.; Waje, M.; and Li, W. 2007. Supportless Pt and PtPd Nanotubes as Electrocatalysts for Oxygen-Reduction Reactions. Angewandte Chemie International 46(22): 4060-4063.

[13] Mattevi, C., Colléaux, F., Kim, H., Lin, Y. H., Park, K. T., Chhowalla, M. and Anthopoulos, T. D. 2012. Solution-processable organic dielectrics for graphene electronics. Nanotechnology. 23(34): 344017.

[14] Zhang, H., Lv, X., Li, Y., Wang, Y. and Li, J. 2009. P25-graphene composite as a high performance photocatalyst. ACS nano. 4(1): 380-386.

[15] Li, X., Zhang, Q., Chen, X. and Gu, M. 2013. Giant refractive-index modulation by two-photon reduction of fluorescent graphene oxides for multimode optical recording. Scientific reports. 3: 2819.

[16] Liu, C., Yu, Z., Neff, D., Zhamu, A. and Jang, B. Z. 2010 Graphene-based supercapacitor with an ultrahigh energy density. Nano letters. 10(12): 4863-4868.

[17] Wang, S. J., Geng, Y., Zheng, Q. and Kim, J. K. 2010. Fabrication of highly conducting and transparent graphene films. Carbon. 48(6): 1815-1823. 